\title{
əSize-Resolved Evaluation of Simulated Deep Tropical Convection
}

\author{
FABIAN SENF \\ Leibniz Institute for Tropospheric Research, Leipzig, Germany \\ DANIEL KLOCKE \\ Hans Ertel Center for Weather Research, Deutscher Wetterdienst, Offenbach, Germany \\ MATTHIAS BRUECK \\ Max Planck Institute for Meteorology, Hamburg, Germany
}

(Manuscript received 11 December 2017, in final form 29 March 2018)

\begin{abstract}
Deep moist convection is an inherently multiscale phenomenon with organization processes coupling convective elements to larger-scale structures. A realistic representation of the tropical dynamics demands a simulation framework that is capable of representing physical processes across a wide range of scales. Therefore, storm-resolving numerical simulations at $2.4 \mathrm{~km}$ have been performed covering the tropical Atlantic and neighboring parts for 2 months. The simulated cloud fields are combined with infrared geostationary satellite observations, and their realism is assessed with the help of object-based evaluation methods. It is shown that the simulations are able to develop a well-defined intertropical convergence zone. However, marine convective activity measured by the cold cloud coverage is considerably underestimated, especially for the winter season and the western Atlantic. The spatial coupling across the resolved scales leads to simulated cloud number size distributions that follow power laws similar to the observations, with slopes steeper in winter than summer and slopes steeper over ocean than over land. The simulated slopes are, however, too steep, indicating too many small and too few large tropical cloud cells. It is also discussed that the number of larger cells is less influenced by multiday variability of environmental conditions. Despite the identified deficits, the analyzed simulations highlight the great potential of this modeling framework for process-based studies of tropical deep convection.
\end{abstract}

\section{Introduction}

Clouds and convection are essential components of Earth's climate system. Their direct influence and their related physical processes strongly shape Earth's radiative energy budget. They couple the atmosphere vertically via convective redistribution of energy, moisture, and momentum and laterally bridge marine and land regions via their interplay with the general circulation (Arakawa 2004; Arakawa and Jung 2011; Stevens and Bony 2013). One particular aspect, the phenomenon of spatial convective aggregation, has gained interest in the climate modeling community, leading to the question of whether the

¿ Denotes content that is immediately available upon publication as open access.

Corresponding author: Fabian Senf, senf@tropos.de organization of convection matters for the mean climate (Holloway et al. 2017; Wing et al. 2017). Clustered organized convection modifies the surrounding environment (drying and warming of the free troposphere and moistening of the boundary), which directly influences the longwave outgoing radiation (Planck response) and feeds back onto its anvil and surrounding boundary clouds (cloud response) (Bony et al. 2016). If there is a systematic dependency of convective aggregation on global surface temperature, then there might be an important climate feedback that is missing in current assessments of climate sensitivity (Khairoutdinov and Emanuel 2013; Mauritsen and Stevens 2015; Mapes 2016).

A considerable part of this climate sensitivity uncertainty can be attributed to an insufficient numerical representation of clouds and convection in general circulation models (GCMs) (Medeiros et al. 2008; Gettelman et al. 2012). GCMs parameterize convection using statistical 
theories that assume a scale separation between convective scales and large-scale dynamics; however, this underlying idea is questionable (Grabowski 2001; Arakawa 2004; Marsham et al. 2013; Birch et al. 2014). Important convective processes, like the triggering [i.e., diurnal cycle; see Bechtold et al. (2014b)] or the evolution of convection [i.e., interaction of multiple cells; see Khairoutdinov et al. (2009); Schlemmer and Hohenegger (2016)], are not captured adequately, which results in biased interactions of the parameterized small scales with resolved larger scales. In tropical regions, these shortcomings are particularly large because convection grows deep quickly, and shallow and deep convection exhibit a complex interplay (Sherwood et al. 2014; Li et al. 2014). For instance, Peters et al. (2017) showed that capturing the observed spatiotemporal structures of tropical rainfall matters for an adequate representation of tropical intraseasonal variability. Especially over the oceans, the intertropical convergence zone (ITCZ) possesses a strong sensitivity to convection parameterization schemes, and even small modifications can lead to large structural differences (Nolan et al. 2016; Möbis and Stevens 2012). The radiative impact of tropical clouds has been shown to dominate possible latitudinal shifts of the ITCZ (Voigt et al. 2014).

We approach the problem of the so-called "convection parameterization deadlock" (Randall et al. 2003; Randall 2013) with large-domain, storm-resolving model simulations that explicitly resolve convection processes. The investigations are focused on the tropical Atlantic and adjacent continents (Klocke et al. 2017) and aim to analyze deep convective characteristics for two different seasons: boreal summer and winter. Simulated features of tropical deep convection are evaluated against infrared Meteosat observations. This idea is motivated by the necessity to test the storm-resolving simulations with novel evaluation approaches that are capable of assessing the additional level of complexity, which is introduced by resolved interacting convection.

The imaging radiometers aboard the geostationary Meteosat platforms are the perfect instruments to characterize convective development and cloud organization due to their frequent temporal update rate and high spatial resolution. There exists a rich record of literature that analyzed deep convection over the tropical Atlantic based on Meteosat data. For instance, Duvel $(1989,1990)$ investigated interannual and diurnal variations of deep convection over tropical Africa and the Atlantic Ocean. They found the existence of a strong coherent diurnal cycle of convective cloudiness over oceanic areas with flow convergence, which is further modulated by propagating easterly waves. Machado et al. $(1992,1993)$ and Machado and Rossow (1993) studied the structural characteristics of tropical convection and their temporal variability using object-based techniques. They found a power law decay of the cloud number size distribution with an exponent around 2. In addition, they demonstrated that high-level cloudiness has a weak maximum over the Atlantic in the early morning and is more pronounced within the troughs of the easterly waves. They also suggested that diurnal variations over the ocean mainly result from internal variations in large mesoscale convective systems (MCSs) and not from new initiation of convection. Furthermore, Schroeder et al. (2009) and Bennartz and Schroeder (2012) analyzed the spatial distribution and the temporal behavior of convective activity using Meteosat observations. The latter found that derived convective activity and minimum convective temperatures are remarkably stable over time and that the longest-living marine MCSs are initiated near the African easterly jet position.

Alongside increasing numerical simulation capabilities and growing availability of high-quality cloud observations, techniques for evaluating simulated tropical cloud characteristics have evolved. The satellite-directed evaluation methods typically invoke a radiative transfer scheme, the so-called satellite forward operator, which translates the simulation output into synthetic satellite radiances that can be directly compared to real observations. The method was advanced by Morcrette (1991), who compared satellite-observed and GCM-based diurnal variability in terms of brightness temperature histograms. Several other investigators improved the use of synthetic Meteosat data for GCM evaluation (Roca et al. 1997; Chaboureau et al. 2000; Chevallier and Kelly 2002; Slingo et al. 2004; Tian et al. 2004; and others), focusing on different dynamical aspects of tropical convection as well as extensions of the method to allow for multispectral (Chaboureau and Pinty 2006; Thelen and Edwards 2013) and even multisensor (Matsui et al. 2014) considerations. Proceeding to finer spatial scales, Zhang et al. (2008) evaluated their superparameterization model (4-km grid spacing) against Meteosat and found that convection was overactive in the considered situations. Finally, very large-domain or even global convectionpermitting simulations have been analyzed by Otkin et al. (2009) (3-km grid spacing) and Sato et al. (2009) (7-km grid spacing), respectively, jointly with Meteosat observations. The latter study especially shows how the confidence about the realism of the numerical simulation can advance understanding of interaction processes in terms of underlying physics.

The advent of convection-permitting simulations increased the demand for novel spatial or object-based evaluation techniques (see, e.g., Ebert 2008; Gilleland et al. 2009). Therefore, several authors developed object-based analysis methods for convection-permitting simulations 
of tropical convection along with Meteosat observations with a focus on convective activity over Africa (Pearson et al. 2010, 2014; Negri et al. 2014; White et al. 2018). They demonstrated that explicitly resolving deep convection improves the representation of convective life cycles, as well as the ability to simulate diurnal cycles and upscale growth of convective cloud clusters. Similarly, Inoue et al. (2008) and Roh and Satoh (2014) analyzed cloud-size distributions of deep convective clouds in the tropical Pacific for their simulations (around 3-km grid spacing) and found good agreement with observed statistics. However, higher model resolutions do not always guarantee improved realism of all aspects of convective cloud characteristics. For instance, Machado and Chaboureau (2015) analyzed a set of convection-permitting forecasts over Brazil and found that the forecasts produced too many small cloud and rain cells with a shorter lifetime than observed. Problems with too many small convection cells were also found by others (e.g., Pearson et al. 2014; Rempel et al. 2017; White et al. 2018), which indicates the general presence of a persistent simulation bias across model versions and setups. With that in mind, we extend the abovementioned studies in two ways. We first focus more on the tropical Atlantic and compare characteristics of marine deep convection to its land-based counterpart for two different seasons. Second, we extend available evaluation techniques by introducing a histogram matching method that is applied before the object-based analysis. This allows for a clearer separation of the assessment of the quality of simulated histograms and the evaluation of spatial structures. In particular, threshold-based analysis techniques, similar to the one we employ, are extremely sensitive to cloud cover biases. In the design of objectbased evaluation metrics, it is therefore very important not to penalize cloud cover or similar shortcomings several times [see, e.g., Rempel et al. (2017) for a discussion of object-based forecast metrics].

The paper is structured as follows. The setup of the cloud-resolving simulations and the observations of the geostationary satellite Meteosat are described in section 2. Section 3 presents the object-based analysis methods, as well as the histogram matching approach for distributional bias correction that is applied in section 4 in order to reveal the spatial distribution and temporal variability of deep moist convection in the tropical Atlantic belt. Final conclusions are given in section 5.

\section{Storm-resolving simulations and satellite data of the tropical land and ocean}

The studied domain covers the tropical Atlantic region from the western parts of Africa to the Caribbean Sea and northeastern parts of South America, with a horizontal extent of more than $9000 \mathrm{~km}$ in east-west direction and more than $3000 \mathrm{~km}$ from south to north (see Fig. 1). The evaluation of simulated deep convection focuses on a boreal summer and a winter month during the Next-Generation Aircraft Remote Sensing for Validation (NARVAL) campaigns (Stevens et al. 2016; Klepp et al. 2014) in August 2016 and December 2013. These two months reflect the reversal points of the tropical Atlantic seasonal cycle. In the following, they are taken as representatives of the winter and summer seasons (Brueck et al. 2015). The domain encompasses the ITCZ in the Atlantic and the related trade wind regions in the north and south of the convergence zone. We define two subregions of the full domain: the inner parts of the tropical Atlantic and the western part of the African continent. We exclude a 300-km-wide stripe centered on the coastal regions to obtain a sufficient separation between land and ocean environments. In summer, the ITCZ is centered at about $10^{\circ} \mathrm{N}$, and deep convective events in the domain are influenced by easterly waves and fast-moving convective storms over Africa (see Fig. 1). In winter, the deep convective activity is focused more in the central tropical Atlantic and farther south at about $5^{\circ} \mathrm{N}$.

\section{a. Storm-resolving simulations}

In support of the NARVAL flight campaign, stormresolving (2.4-km grid spacing) simulations of the tropical Atlantic for every day in December 2013 and August 2016 were performed (Klocke et al. 2017) using the Icosahedral Nonhydrostatic (ICON) model (Zängl et al. 2015) of the German Weather Service (DWD) and the Max Planck Institute for Meteorology. Thirty-six-hour forecasts are initialized for each day of the two months at 0000 UTC with the atmospheric analysis product from the European Centre for Medium-Range Weather Forecasts (ECMWF) and are nudged on the lateral boundaries with the corresponding 3-hourly forecast data. Because of the relatively high resolution of ICON, the parameterizations for convection, gravity wave drag, and subgrid-scale orography are not used. The first $12 \mathrm{~h}$ of each simulation are discarded due to artifacts from the initialization and to allow for the small-scale phenomena to develop from the coarser (16 km for December 2013 and $9.5 \mathrm{~km}$ for August 2016) initial fields [similar to Maurer et al. (2015)]. The full model state is saved every hour and serves as an input for the calculation of synthetic radiances, as described in the following.

\section{b. Synthetic radiances from simulation data}

A satellite forward operator has been applied to the thermodynamic and hydrometeor fields from the model 
(a) Meteosat SEVIRI

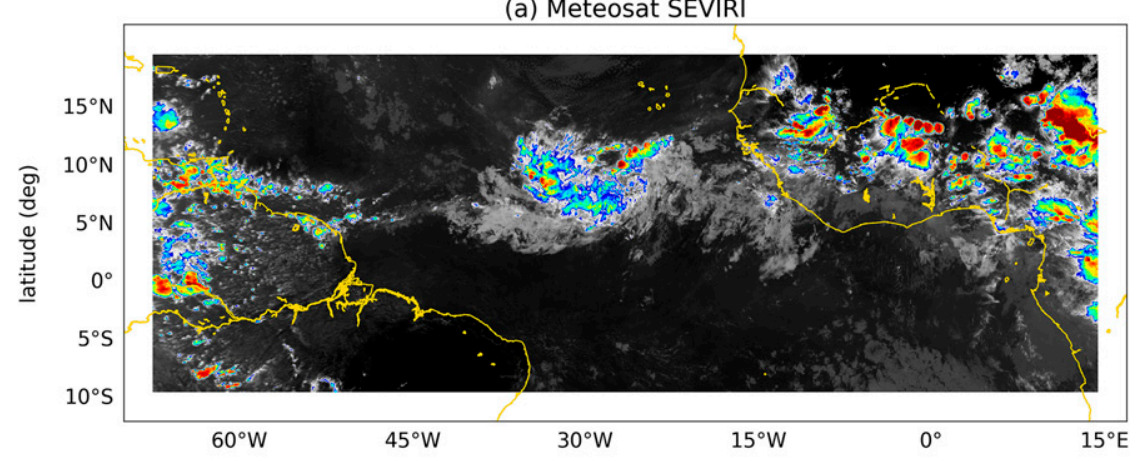

(b) Synthetic ICON

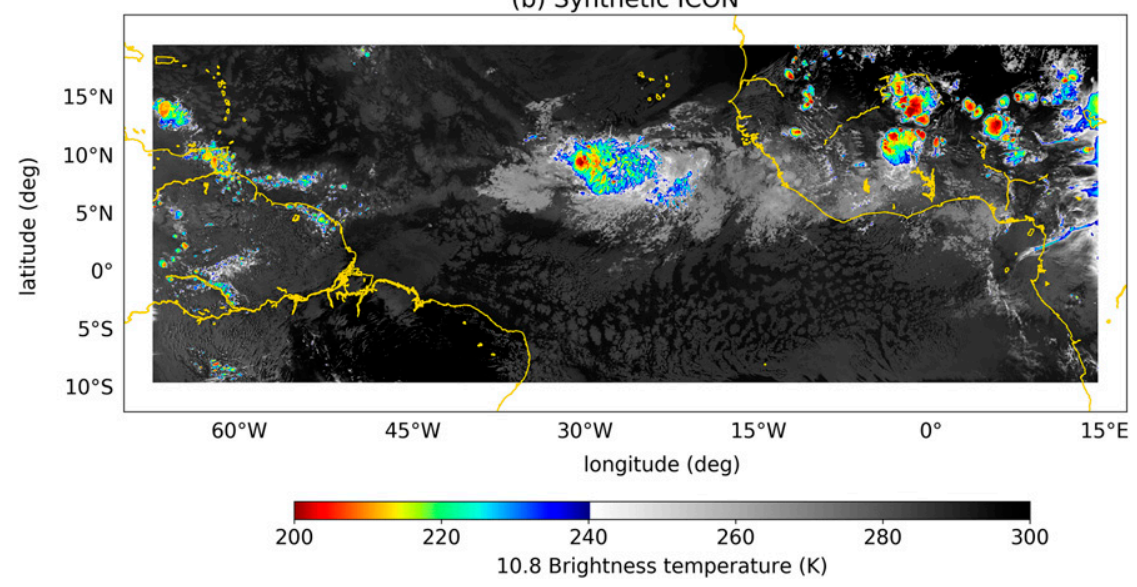

FIG. 1. Brightness temperature fields for (a) Meteosat observations and (b) synthetic ICON imagery at 1800 UTC 15 Aug 2016. Color shading indicates low BTs, with values lower than $240 \mathrm{~K}$.

to compute the simulated radiation with spectral characteristics of Meteosat Spinning Enhanced Visible and Infrared Imager (SEVIRI). We employ the so-called SynSat method (Keil et al. 2006; Senf and Deneke 2017) that prepares model output variables (namely, profiles of air pressure, temperature, moisture, and hydrometeor content), as well as surface properties, and sequentially performs single-column radiative transfer calculations with the RTTOV model version 11 (Saunders et al. 1999). In a preparation step, cloud-radiative properties are estimated from the hydrometeor mass mixing ratios. We choose the operational configuration in which cloud ice and precipitating snow masses are added, and the McFarquhar et al. (2003) scheme is applied to estimate the effective crystal sizes from which scattering and absorption coefficients are derived. The simulated infrared radiances are converted into equivalent blackbody temperatures, called brightness temperatures (BTs) in the following. Note that the applied simplifications in the description of microphysical properties and, consequently, the infrared radiative cloud characteristics are typically inconsistent with model-internal formulation and can lead to uncertainties of simulated brightness temperatures on the order of a few kelvin [see, e.g., Senf and Deneke (2017) for further discussion].

\section{c. Satellite data}

Measurements of the SEVIRI instrument on board the Meteosat Second Generation (MSG) geostationary satellite are used for evaluation of simulated convection. We analyze hourly SEVIRI data from the operational MSG prime service operated at a nominal subsatellite longitude of $0^{\circ}$. The horizontal resolution of measured radiances is $3 \mathrm{~km}$ at the equator and increases toward the poles. SEVIRI covers a broad range of the solar and terrestrial radiation spectrum, with a total of 12 channels. For simplicity, we only use two infrared channels here, centered at 6.2 and $10.8 \mu \mathrm{m}$. The former is strongly affected by absorption from atmospheric water vapor. Most of the signal emitted at $6.2 \mu \mathrm{m}$ comes from the upper troposphere between 200 and $300 \mathrm{hPa}$. The spatial distribution of $6.2-\mu \mathrm{m}$ radiation either reflects the distribution of upper-tropospheric water vapor or that of 
(a) visible

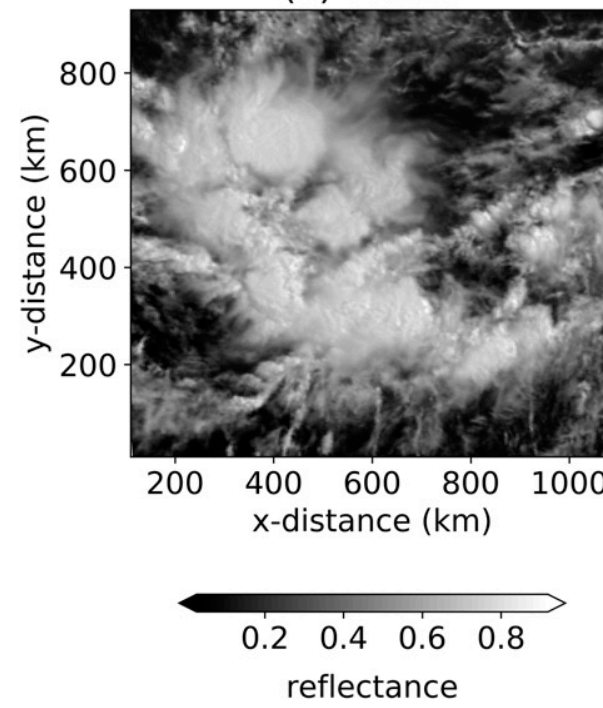

(b) infrared
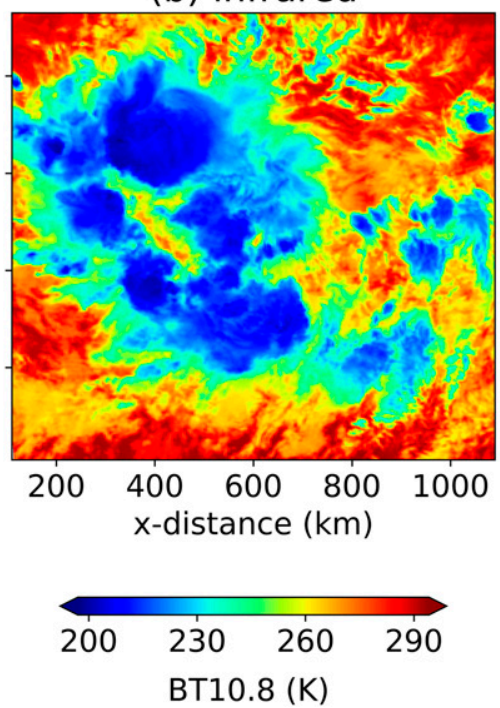

(c) segmented field

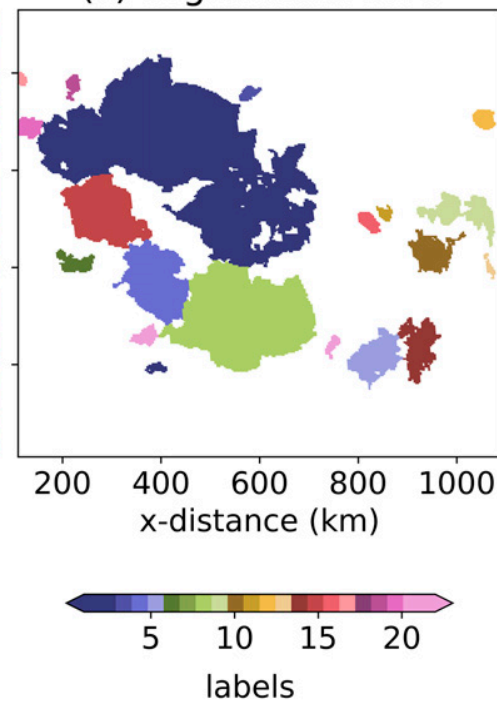

FIG. 2. Illustration of the segmentation method. Small regional excerpt of Meteosat observations of an organized convective system over the tropical Atlantic showing (a) visible reflectances at $0.6 \mu \mathrm{m}$, (b) BT10.8, and (c) result of the segmentation method when a BT10.8 threshold of $230 \mathrm{~K}$ is applied. The observation is from $1200 \mathrm{UTC} 15 \mathrm{Aug} 2016$, the lower-left corner lies at $4.33^{\circ} \mathrm{N}, 33.59^{\circ} \mathrm{E}$, and spatial coordinates are measured relative to that corner.

very cold clouds. The second channel, at $10.8 \mu \mathrm{m}$, is located in the atmospheric window, which means that radiation is only slightly influenced by absorption from atmospheric gases. The main signal thus comes from the land or ocean surfaces or the top layers within clouds or a combination of the two.

For comparison, the observed brightness temperatures have been reprojected and regridded onto the model grid. An example of the $10.8-\mu \mathrm{m}$ brightness temperature (BT10.8) is shown in Fig. 1 for 1800 UTC 15 August 2016. Clouds with a cold top temperature (highlighted with colored shadings) mark the positions where deep moist convection is most active and reaches to high atmospheric altitudes. In this particular example, deep convection over the tropical Atlantic is modulated by large-scale wave-like features and is highly organized in convectively active regions.

\section{An object-based method to evaluate deep convective clouds}

\section{a. Object-based analysis}

Object-based analysis methods might allow for deeper insights into the temporal evolution and spatial characteristics of convective clouds than standard techniques, based on comparison of gridpoint values or regional value distributions (see, e.g., Ebert 2008; Gilleland et al. 2009). We therefore convert simulated and observed BT10.8 fields into sets of cell objects using a threshold-based segmentation technique. An illustration is given in Fig. 2, and further details are described in appendix A. One prime advantage of our applied segmentation procedure is that we are able to consistently split up filament connections between visually separate cloud cells, compared to standard methods that use connected compound analysis (e.g., Wielicki and Welch 1986; Machado et al. 1992; Negri et al. 2014; Rempel et al. 2017).

A BT10.8 threshold of $230 \mathrm{~K}$ has been chosen, which roughly corresponds to a height of $11 \mathrm{~km}$ in a standard tropical atmosphere (Machado et al. 1992). This temperature threshold is identical to the threshold considered in Schroeder et al. (2009) and Bennartz and Schroeder (2012) to assess the distribution of convective activity over Africa and the tropical Atlantic. With BTs lower than $230 \mathrm{~K}$, only the deep convective cores and the upper parts of thick convective anvil clouds are taken into account. Quite a large diversity on threshold choices can be found in the literature, however [e.g., see discussion in Bennartz and Schroeder (2012)].

The cells are analyzed using a set of standard objectbased metrics (see, e.g., Rempel et al. 2017). For instance, the size of each cloud object with index $i$ is defined by its equivalent diameter $D_{i}=2 \sqrt{a_{i} / \pi}$, which is the diameter of an area-equal circle with area $a_{i}$. Based on the equivalent diameters, we build size-resolved statistics. The number of cells $N_{k}$ is counted for different size categories defined by logarithmic size intervals $\left(D_{k-1}, D_{k-1}+\Delta D_{k}\right)$, with 
$\Delta D_{k}=c D_{k-1}, c=0.229$, and $D_{0}=20 \mathrm{~km} ; k=1, \ldots, 20$ denotes the size range index [similar to Machado et al. (1992)]. Cloud number size distributions (CNSDs) have been computed as cell number density per size interval via

$$
n_{k}=\frac{1}{\Delta D_{k}} \frac{N_{k}}{A_{\mathrm{reg}}},
$$

where $A_{\text {reg }}$ refers to the area of the analysis region (e.g., the tropical Atlantic and western Africa). We do not apply a size-dependent bias correction of the analysis area $A_{\text {reg }}$, as proposed by Wood and Field (2011), to correct for removed large cells that are connected to the domain edges. We furthermore compute cloud cover distribution functions (CCDFs), which give size dependence of relative cold cloud coverage. In contrast to the CNSD, the CCDF was normalized with respect to the logarithmic bin size $\Delta \log \left(D_{k}\right)$, that is,

$$
f_{k}=\frac{1}{\Delta \log \left(D_{k}\right)} \frac{A_{k}}{A_{\text {reg }}},
$$

to highlight the cloud cover contributions coming from the different scale ranges. The latter involves $A_{k}=\sum_{i \in I_{k}} a_{i}$, which is the area covered by all cells within a certain size range with index $k ; I_{k}$ is the cell index set for all cells that belong to $k$. Based on the CCDF, we define a median cell diameter $D_{50}=D_{k^{*}}$, for which one-half of the cloud coverage originates from cells with smaller diameters, whereas the other half comes from larger cells; that is, $k^{*}$ is determined from the implicit relation

$$
\sum_{k>k^{*}} f_{k}=\sum_{k<k^{*}} f_{k},
$$

after Wood and Field (2011). Based on the temporal analysis discussed in appendix B, area rates are calculated as instantaneous changes in anvil area. Cells that possess larger area rates than the upper quartile are termed actively growing, whereas cells with area rates smaller than the lower quartile are termed dissipating.

\section{b. Bias correction of simulated BTs}

We base our evaluation of simulated tropical convection on the comparison of simulated and observed BTs. As we will show in section 4, the average frequency distribution of simulated BTs deviates significantly from the observations over a broad range of BT values. These histogram biases carry information about deficits in our ability to realistically simulate deep convective development and organization processes and, to a lesser extent, about the shortcomings in the satellite forward operator. Hence, understanding simulation biases might help us to improve our models and their configuration. On the other hand, these biases do negatively influence our ability to identify similarities and differences in spatial structures of deep convective clouds and their temporal variability. By the term "spatial structures," we mean the relative arrangement of field values rather than their absolute values. This information might be assessed based on the rank of the individual values in a more robust manner. In that sense, we propose to separate the model evaluation into two tasks: (i) the analysis of BT histograms and (ii) the comparison of spatial structures from the rank fields. To stay within the BT space, we transform the simulated rank fields back using histogram matching, which is explained in the following.

We determine the cumulative distribution functions (CDFs) for observed and simulated BT10.8s. We use descending BT order; that is, CDFs give the probability that a BT value is smaller than a certain threshold. CDFs are accumulated over full months. The result for August 2016 is shown in Fig. 3a. For instance, the probability is $3.6 \%$ to observe a BT10.8 smaller than $230 \mathrm{~K}$, but $2.2 \%$ only for simulated BT10.8s. The inverse CDFs map a certain probability or percentile value to corresponding BT10.8 thresholds. Now, taking the average observed coverage of $3.6 \%$, a simulated BT threshold of $240.9 \mathrm{~K}$ would result. Hence, aiming to match observed and simulated cold cloud coverage, an increase in the simulated BT threshold of around $11 \mathrm{~K}$ would be needed. This is a significant cloud cover bias for which we have to correct before the application of object-based evaluation metrics. In other words, if we apply a BT bias correction of $-11 \mathrm{~K}$ to the simulated BT10.8 around $241 \mathrm{~K}$, we adjust the simulated cloud cover to the observed counterpart (see arrows in Fig. 3a). In the following, the bias correction is applied to the simulated BT10.8 distribution gathered for the full domain. The BT distributions are accumulated for each of the two months, separately, to obtain mapping functions. Thereafter, simulated BTs are mapped onto the typically observed BTs that have equal percentile values. This method is also known as histogram matching in the image-processing community. The results based on bias-corrected BT10.8s are labeled by "ICON-t" and are shown together with the uncorrected simulated BTs.

The applied BT10.8 bias correction for the two months is presented in Fig. $3 \mathrm{~b}$ as a function of simulated BT10.8. The BT10.8 correction is mainly negative over a broad range of low BTs and on the order of $10 \mathrm{~K}$. This is related to a positive BT bias of the simulations, indicating too-low cloud tops and too-small convective anvils, which is slightly more pronounced in August 2016 than in December 2013. Furthermore, Fig. 3b also shows a hypothetical spread of the BT bias correction if 
(a) Histogram Matching Method

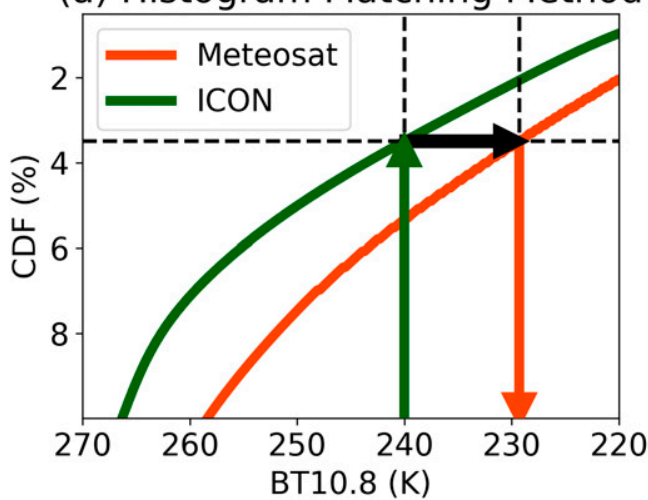

(b) BT correction function

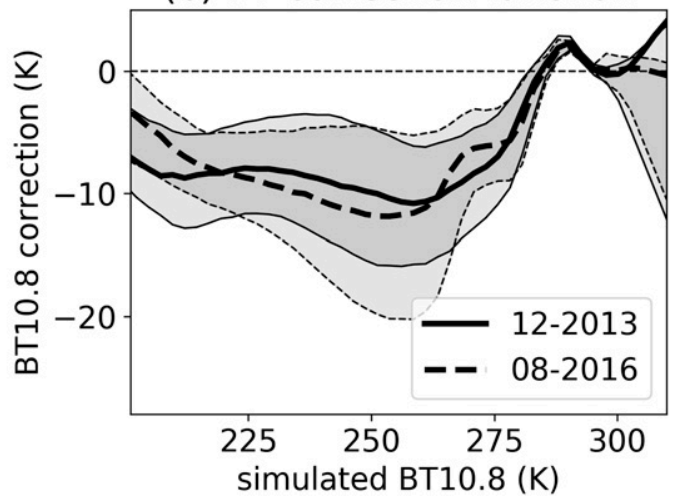

FIG. 3. Bias correction for simulated ICON BT10.8 data using histogram matching. (a) Based on the aggregated CDFs of ICON (green line) and Meteosat (orange line), a mapping is performed that transforms simulated BT10.8 to observed BT10.8 possessing the same CDF values (see section 3b). (b) The average BT10.8 correction (thick lines) has to be added to the simulated BT10.8 (on abscissa) to map the average simulated BT10.8 distribution to its observed counterpart. The mapping is derived for two time periods: December 2013 (solid lines) and August 2016 (dashed lines). The shaded interval between the thin lines gives the 16th- to 84th-percentile range of hypothetical BT10.8 corrections if the BT10.8 mapping would be derived for each time slot separately. This hypothetical spread is only shown for illustration purposes and was not used for bias correction in the current study.

the histogram matching technique would be applied on hourly and not on monthly average basis. It illustrates that cold cloud coverage bias is a very persistent feature of the ICON simulations besides the large temporal variability.

\section{Results}

\section{a. Monthly average cloud statistics}

Subsequently, monthly average cloud statistics are analyzed, for which we contrast similarities and deviations between observations and simulations. Full-domain probability density functions (PDFs) of BT10.8 and BT6.2 are compared in Fig. 4. The PDFs of observed BT10.8 show a frequency peak around $293 \mathrm{~K}$, which is related to the surface temperature of the cloud-free ocean. However, the simulated BT10.8 PDFs show a peak that is shifted to $288 \mathrm{~K}$, which is close to the cloud-top temperature of marine low-level clouds. Hence, the simulations overestimate the low-level cloudiness over the subtropical parts of the ocean, which is probably caused by the too-coarse model resolution for the proper representation of shallow convection, a common consequence from too little mixing in the boundary layer (Bechtold et al. 2014a). At the low BT10.8 tail, the distributions follow approximately the same shape but exhibit an offset of around $10 \mathrm{~K}$, as mentioned in section $3 \mathrm{~b}$. As a result, the cold cloud coverage with $\mathrm{BT} 10.8<230 \mathrm{~K}$ is underestimated up to a factor of 2 . This cloud cover bias is more pronounced over the ocean (see Table 1). The BT offset is relatively stable across a considerable BT10.8 range (also see Fig. 3). This circumstance led us to suspect that the underestimation of cloud cover is mainly caused by an underestimation of cloud-top height and, thus, overestimation of cloud-top temperatures. This further motivates the analysis of ICON-t properties to investigate if the structural characteristics of simulated convection show a higher degree of realism. Furthermore, Fig. 4 shows the average distributions of BT6.2, which is connected to upper-tropospheric water vapor. Large-scale dry patches lead to the occurrence of a broad BT6.2 PDF maximum around $240 \mathrm{~K}$. The simulations closely follow the observed curve. An underestimation of low BT6.2 frequencies and corresponding compensation within the peak region is again caused by the cold cloud cover bias. Therefore, the large-scale upperlevel moisture patterns are well represented in the simulations. This is in contrast to the simulations over tropical Africa, analyzed by Negri et al. (2014), for which a pronounced dry bias of upper-level moisture was found.

In the following, we focus on object-based analysis of tropical deep convection. Average cell characteristics are derived from observed and simulated BT10.8 values colder than $230 \mathrm{~K}$ and are shown in Fig. 5 for the summer season over the Atlantic Ocean. Additionally, computations of cold cloud coverage, average nearest-neighbor distance, and CNSD power law exponents are provided in Table 1, which supplements the graphical representation in Fig. 5. Results for the bias-corrected ICON-t are presented in addition to the uncorrected simulation 


\section{Average BT occurrence frequencies}

(a) BT10.8 (K) @ 201312

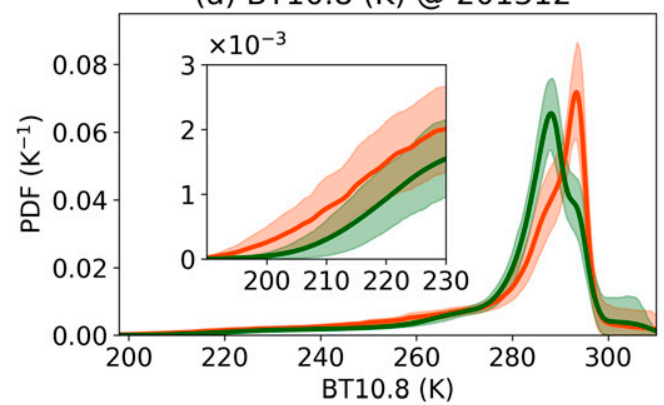

(c) BT10.8 (K) @ 201608

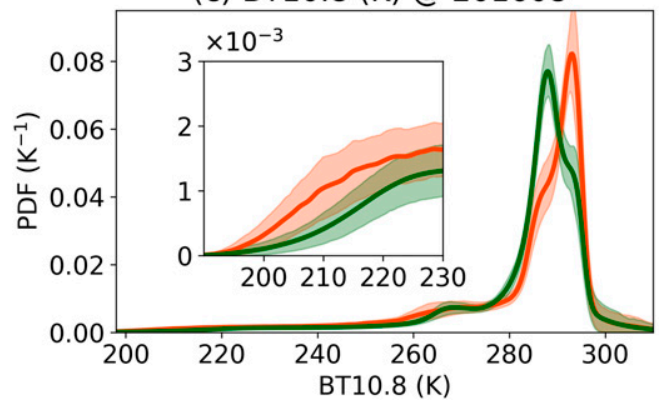

(b) BT6.2 (K) @ 201312

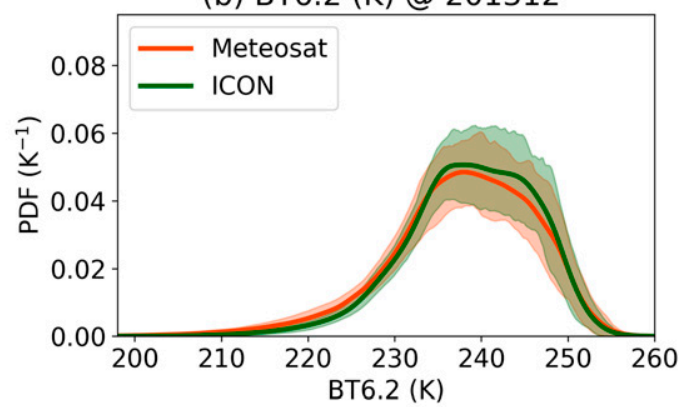

(d) BT6.2 (K) @ 201608

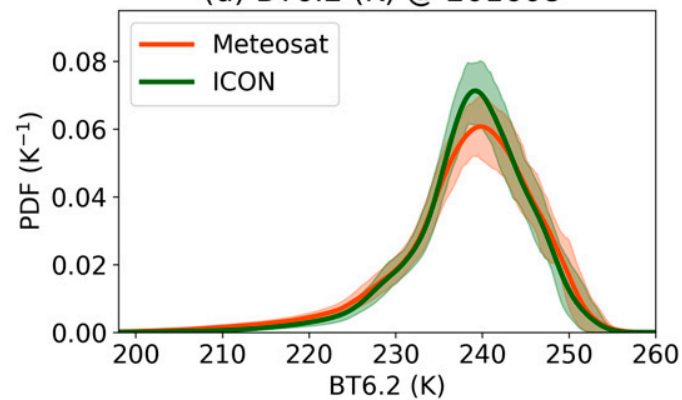

FIG. 4. Occurrence frequencies of (left) BT10.8 and (right) BT6.2 for (a),(b) December 2013 and (c),(d) August 2016. Observation (orange) is compared to the simulation (green). Normalization with BT bin-width is applied to obtain probability density functions. The average occurrence frequency is given by the solid line, and the range between the 16th and 84th percentiles (corresponding to \pm standard deviation) is plotted as semitransparent shadings. Insets in (a) and (c) zoom into the PDF for the low BT range below $230 \mathrm{~K}$.

values (ICON). In general, the bias correction leads to an improvement of considered cell metrics over the ocean (with some exceptions, especially over the land; not shown), which means that the simulated cloud structures are relatively close to the observations. From Fig. 5a, it appears that the observed and simulated CNSDs can be represented by a power law over a large range of sizes (i.e., $n_{k} \sim D_{k}^{-\beta}$ ). The negative power law

TABLE 1. Cold cloud coverage (in \%) under the condition of BT10.8 $<230 \mathrm{~K}$ (first block), average nearest-neighbor distances (second block), and power law exponents $\beta$ of the cloud number size distribution (third block) for two subregions, Africa and Atlantic, and the Meteosat observation as well as the ICON simulation with and without bias correction. Mean power law exponent values and $90 \%$ confidence intervals (in parentheses) are obtained from repeated linear least squares fits using a bootstrap approach. Absolute frequencies are assumed to be realizations of Poisson processes. Boldface scaling coefficients indicate simulated values that are significantly different from observation at $1 \%$ level.

\begin{tabular}{|c|c|c|c|c|}
\hline & \multicolumn{2}{|c|}{ Tropical Atlantic } & \multicolumn{2}{|c|}{ Western Africa } \\
\hline & Dec 2013 & Aug 2016 & Dec 2013 & Aug 2016 \\
\hline \multicolumn{5}{|c|}{ Cold cloud coverage in $\%$} \\
\hline Meteosat & 1.9 & 1.7 & 0.9 & 5.7 \\
\hline ICON & 0.7 & 0.9 & 0.5 & 4.9 \\
\hline ICON-t & 1.5 & 1.5 & 0.9 & 7.3 \\
\hline \multicolumn{5}{|c|}{ Average nearest-neighbor distances: Average (mode) in km } \\
\hline Meteosat & $128(61)$ & $126(68)$ & $192(65)$ & $151(66)$ \\
\hline ICON & $115(52)$ & $104(56)$ & $175(69)$ & $126(58)$ \\
\hline ICON-t & $97(51)$ & $101(55)$ & $134(45)$ & $112(55)$ \\
\hline \multicolumn{5}{|c|}{ CNSD power law exponents: Expected value (confidence interval) } \\
\hline Meteosat & $2.6(2.8,2.5)$ & $2.3(2.4,2.2)$ & $2.6(3.0,2.4)$ & $2.1(2.2,2.0)$ \\
\hline ICON & $3.3(3.5,3.1)$ & $2.8(3.0,2.7)$ & $3.2(3.5,2.9)$ & $2.2(2.3,2.1)$ \\
\hline ICON-t & 3.1 $(3.3,3.0)$ & $2.6(2.8,2.6)$ & $3.3(3.6,3.0)$ & $2.3(2.4,2.2)$ \\
\hline
\end{tabular}




\section{Tropical Atlantic @ 2016-08}

(a) Cloud Number Size Distribution

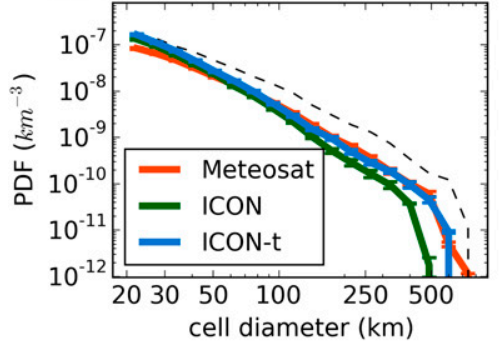

(d) Mean and min. BT10.8 Ratio

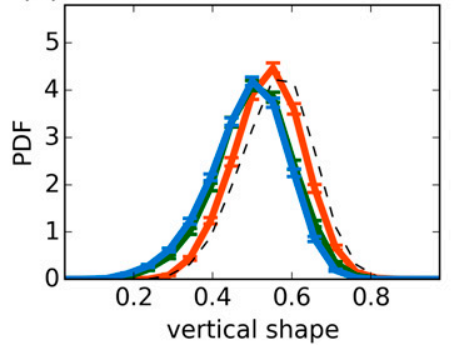

(b) Cloud Cover Distribution

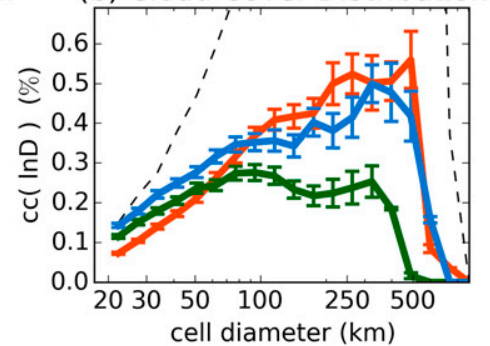

(e) Horizontal Aspect Ratio

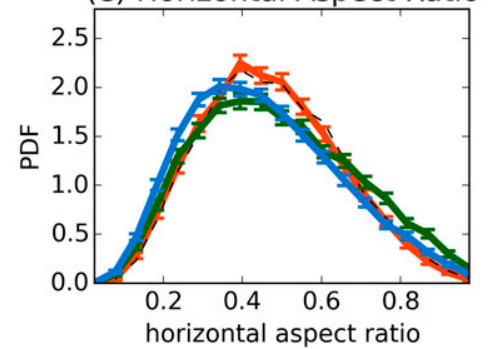

(c) Cloud Nearest Neighbor Distance

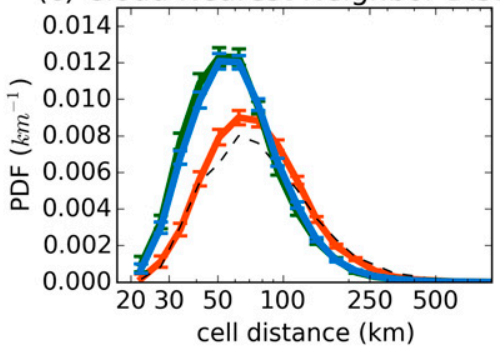

(f) Minimum BT10.8

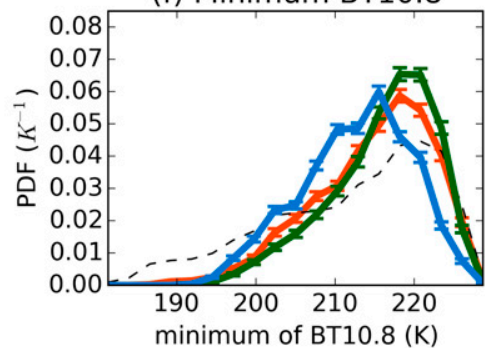

FIG. 5. Object-based statistics for August 2016 and the tropical Atlantic. Shown are (a) cloud number size distribution $n_{k}$, (b) cloud cover distribution function $f_{k}$, (c) cloud nearest-neighbor distance, (d) the vertical-shape parameter (i.e., the ratio between mean and minimum BT10.8), (e) the ratio between horizontal dimensions, and (f) the cell minimum BT10.8 values. The monthly average distribution (thick solid line) and its standard error due to temporal variability (error bars) is given for Meteosat observations (orange), unmodified ICON simulations (green), and bias-corrected ICON-t (blue). The black dashed lines present the average observed distributions over land for the same time period. The cloud number size distribution is normalized with respect to diameter $D$ and divided by domain area; the cloud cover distribution is, however, normalized with respect to $\ln D$.

slopes $\beta$ are between 2.1 and 2.6 for observation and between 2.2 and 3.3 for simulations (see Table 1), with considerable uncertainty. This is in line with Machado et al. (1992), who found slopes of Meteosat-derived CNSD varying around 2 for similar BT ranges. Slightly larger slopes of 2.6 to 2.9 and of 3.1 were reported by Wood and Field (2011) and Peters et al. (2009), respectively (reported exponents were recalculated by us from the original exponents $\beta^{\prime}$ using the formula $\beta=2 \beta^{\prime}-1$, which accounts for the variable transformation going from CNSDs per area interval to CNSDs per diameter interval). The two studies based their analyses on very different spaceborne observations; the former studied cells derived from cloud masks, whereas the latter based their study on radar-derived precipitation cells. Both studies also discussed the universality of the power law behavior and the link to simplified models, a bounded cascade model for Wood and Field (2011) and a gradient percolation model for Peters et al. (2009), highlighting the fractal nature of the cloud-precipitation system. It was further discussed by Peters and Neelin (2006) and Peters et al. (2009) that scale-free CNSDs might originate from an underlying critical behavior, with water vapor amount as control parameter.
The quantitative agreement of CNSD power law exponents with previous studies is not trivial, as different analysis methods have been applied, and it shows that our watershed-based segmentation technique beside methodical differences leads to a similar partitioning between smaller and larger cells. The observed slopes are typically steeper in winter than in summer, which suggests that deep convective clouds are slightly less organized during the winter season. In the summer season, the observation attains steeper slopes over the ocean than over the land. Similar to Wood and Field (2011), larger slope values are obtained for smaller cold cloud coverage. Simulated slopes capture the seasonal and land-ocean differences. However, the simulated slopes are typically too steep, even for ICON-t, indicating too many small and too few very large tropical cloud cells in the simulations. Additionally, Fig. 5b shows size dependence of relative cold cloud coverage. When a $\beta$ value of around 3 is approached, the contribution of smaller cells to area-integrated properties like cloud fraction and accumulated precipitation becomes more and more important (Wood and Field 2011). Consistent between observation and simulation, larger cells contribute more to cloud coverage than smaller 
cells do. We also see that the simulations begin to resolve spatial scales that are small enough that resolution limitations only have a minor impact on the total cold cloud coverage. The average observed nearest-neighbor distance is on the order of $120 \mathrm{~km}$ over the ocean and $150 \mathrm{~km}$ over land in the summer season (see Fig. $5 \mathrm{c}$ and Table 1). The nearest-neighbor distance distributions are heavily skewed toward larger distances. Simulations underestimate the typical nearest-neighbor distances, which could be due to the larger number of simulated small cells or could even be an indication that the simulations show a higher degree of convective organization in terms of more clustered spatial cloud arrangement.

Two cell-shape metrics are discussed in the following. First, the ratio between average and maximum BT10.8 excess over the threshold value (shown in Fig. 5d) can be interpreted as vertical shape of the objects [see, e.g., Wernli et al. (2008); Rempel et al. (2017) for more detailed discussion]. Values close to zero indicate more peaked objects, whereas values close to 1 indicate flatter objects. The vertical-shape parameter is larger for the observations, meaning that the observed cold cloud cells are slightly flatter. Second, PDFs of the horizontal aspect ratio between minor and major object axes are presented in Fig. 5e. The average observed horizontal aspect ratio is around 0.5 , meaning the major cell axis is around twice as large as the minor cell axis. The PDF of the horizontal aspect ratio is much broader than the PDF of the vertical-shape parameter. On average, simulated cells have slightly smaller aspect ratios; hence, they are slightly more elongated, compared to the observation. Finally, the cell minimum BT10.8 is shown in Fig. 5f. Over the ocean and the summer season, the most probable value for the observed BT minimum is around $220 \mathrm{~K}$. Around $30 \%$ of the observed cells have colder BT10.8 minima than $210 \mathrm{~K}$, and only $5 \%$ of the cells are colder than $200 \mathrm{~K}$. For the winter season (not shown), the probabilities reduce to $18 \%$ and $4 \%$ for 210 and $200 \mathrm{~K}$, respectively. Over land, we have $40 \%$ and $18 \%$ for minimum BTs colder than 210 and $200 \mathrm{~K}$ for the summer season, respectively. During wintertime and over land, relative occurrence frequencies of minimum BT values are only around half of the respective summertime values. In general, the simulations are able to capture the differences between the seasons and between land and ocean. The occurrence frequency of cold core temperatures $(<210 \mathrm{~K})$ is mainly underestimated in uncorrected ICON simulations. In contrast, the bias correction leads to an overcompensation of core temperature occurrence rates over the ocean, which highlights that bias-corrected ICON-t results have to be carefully interpreted and are more meaningful for structural cell metrics.
For the winter season, Meteosat observations show a broad band of convective activity over the tropical Atlantic, with a maximum in the central part of the ocean (see Fig. 6). Over Africa, the activity is mainly located at the coastal regions around the equator. The main part of observed activity is caused by medium-size cells between 150 and $400 \mathrm{~km}$. Persistent clusters of large cells $(>400 \mathrm{~km})$ are also observed in the tropical Atlantic. While the simulated deep convective clouds cover, in general, the right areas, convective activity over the tropical ocean is underestimated in the boreal winter season. The underestimation is mainly resulting from the simulation of too few of the largest convective cells. Bias correction only slightly improves this, which means that the cell-size underestimation is a robust structural deficit. For August, the band of observed convective activity is slightly shifted northward, with a more narrow appearance, especially in the western Atlantic. The convective activity over the ocean is linked to western Africa. The simulation realistically represents the distribution of convective activity over land across the cell-size spectrum. Over ocean, the distribution of simulated small cells is closer to the observation than for larger cells. The largest simulation deficits appear for the largest cold cloud cells and in the western Atlantic region.

We further assess the spatial distribution of typical cell sizes, which is shown in Fig. 7. The analysis is based on median cell diameters $D_{50}$, defined by Eq. (3) after Wood and Field (2011), for which local CCDFs have been computed on a regular $1^{\circ} \times 1^{\circ}$ longitude-latitude grid. Observed median cell sizes reach several hundred kilometers in the ITCZ region, which is in contrast to Wood and Field (2011), where no pronounced signal of organized deep convection was shown, probably due the dominance of smaller low- to medium-level clouds. Simulated median cell sizes are underestimated over the ocean in both seasons. In general, the observation in comparison to simulation shows much larger and therefore more persistent cells in the winter season. However, the simulations capture the development of larger convective clusters over land during summer. In this season, simulated cloud cell sizes over the western part of the Atlantic are considerably too small.

The average spatial distribution of growing versus decaying cold cloud cells is considered in Fig. 8. To obtain the resulting figure, the Lagrangian cell area change is calculated as explained in appendix B. Then, the temporal area rates are assigned to the objects, and areaweighted statistics are applied (i.e., the area rate is counted for each object pixel). Thereafter, the number of times is calculated in which the local area rates fall below or are above the average interquartile range. 

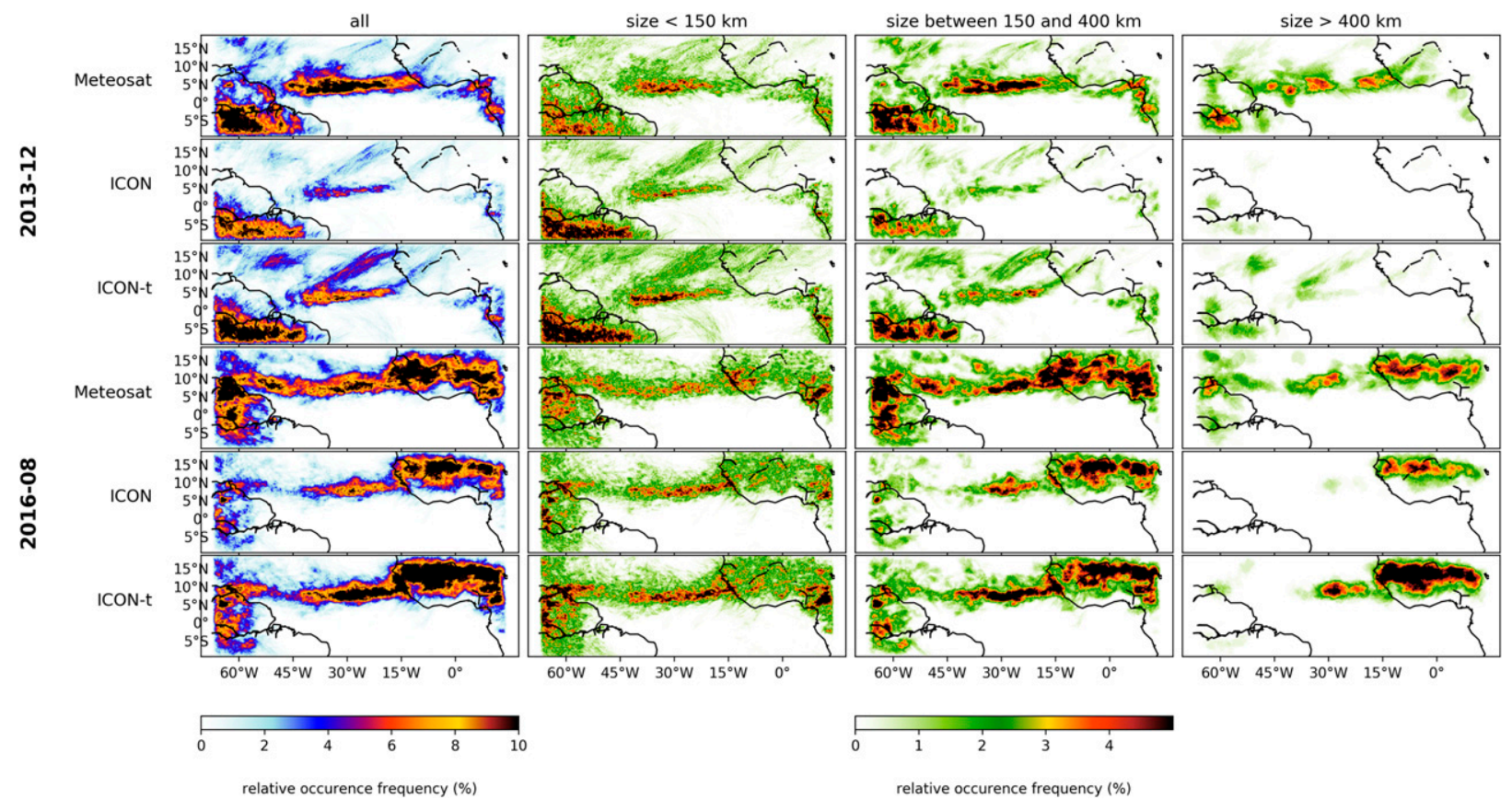

FIG. 6. Spatial distribution of cold cloud coverage for different cell-size intervals for (first block of three rows) December 2013 and (second block of three rows) August 2016. Contrasted are Meteosat observation (first line in each block), ICON, and bias-corrected ICON-t simulations (second and third lines in each block). Cold cloud coverage is defined as the relative fraction of a certain grid box that has a BT10.8 value lower than $230 \mathrm{~K}$ and belongs to a cloud cell within a selected size range. We choose different size conditions (from left to right column): all cell sizes, sizes smaller than $150 \mathrm{~km}$, sizes between 150 and $400 \mathrm{~km}$, and sizes larger than $400 \mathrm{~km}$. Note that different color tables have been used.

Finally, the local difference between growing (above 75 th percentile) and decaying (below 25 th percentile) is plotted. Hence, the number difference fields show where more cells decay or grow on average in a certain region. In the winter season, observations show a broad band from the coast of West Africa to the western Atlantic, where cell growth is more frequent than decay. This connection between coastal parts and the central ocean is not apparent in the simulations. Simulated enhanced activity over the ocean is slightly shifted northward. In the summer season, observed as well as simulated convective activity is enhanced over western Africa, as
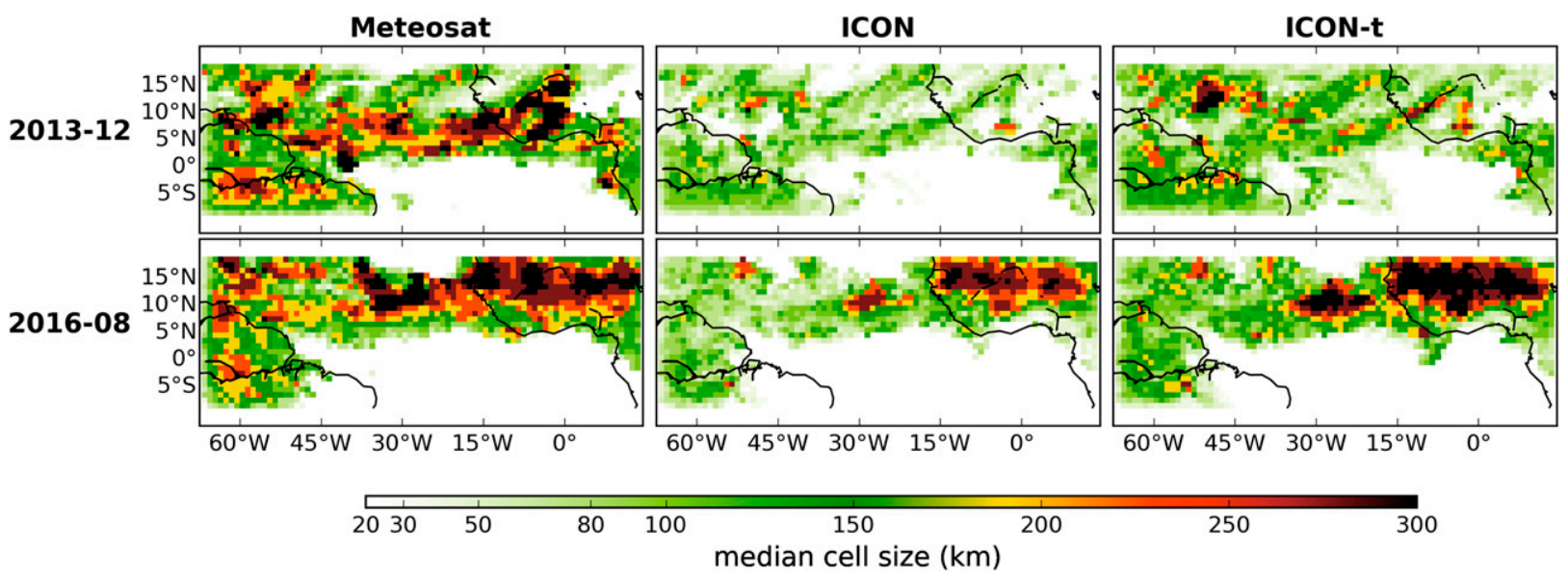

FIG. 7. The spatial distribution of median cell size $D_{50}$ for the time periods of (top) December 2013 and (bottom) August 2016. Compared are (left) Meteosat observations, (middle) ICON simulations, and (right) bias-corrected ICON-t. The median size was calculated using Eq. (3), based on local CCDFs that were computed on a regular $1^{\circ} \times 1^{\circ}$ longitude-latitude grid. 

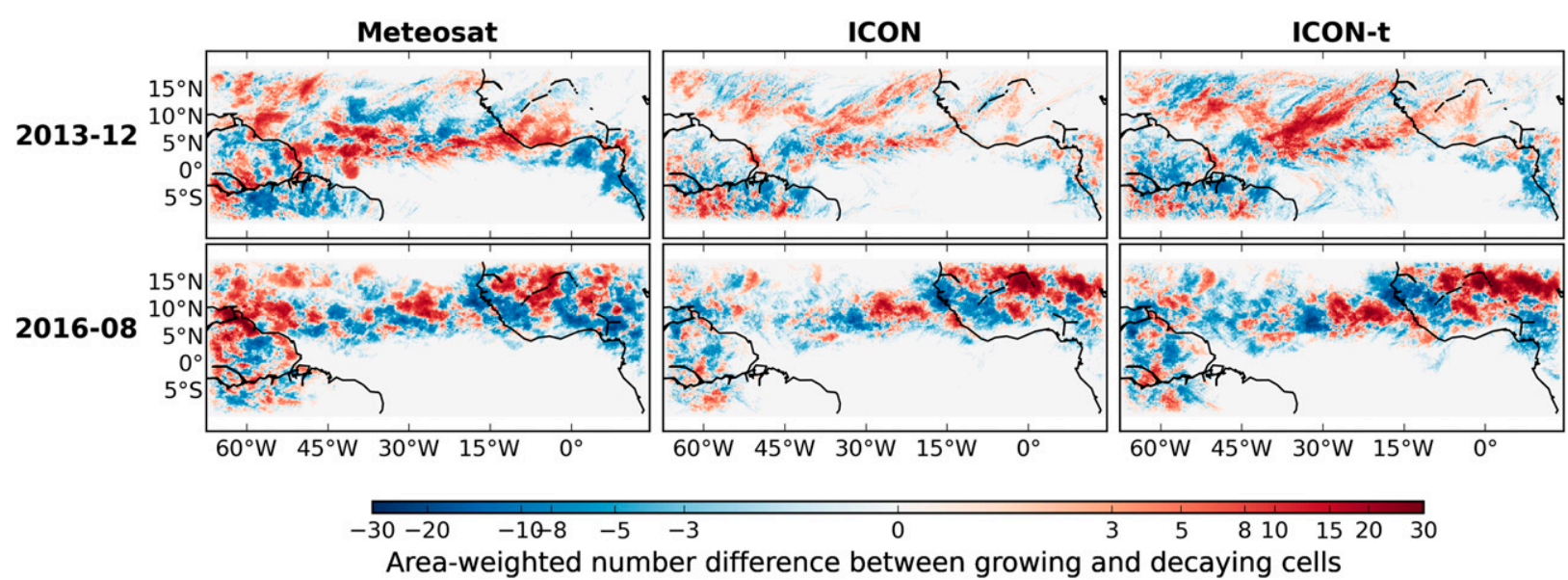

FIG. 8. Spatial distribution of anvil growth and decay. The maps show the absolute number difference between time slots where actively growing cold cloud coverage and strongly decaying cold cloud coverage was retrieved. The instantaneous temporal change in cell area was used as cell growth proxy. The number of active time slots was defined as the number of times when the 75th percentile of the total area rate distribution was exceeded. Similarly, strong decay was defined as area shrinking, with values below the 25 th percentile of the same area rate distribution.

expected from the climatology of the region (e.g., Nicholson 2013). We also recognize wavelike features in both the observation and in the simulation, with more frequent decay in the African coastal regions and again enhanced growth farther westward over the ocean. This compares well with Kouadio et al. (2010), who investigated the precursor MCSs of tropical hurricanes and showed that these MCSs typically initiated in western Africa and dissipated over the Atlantic or near the African coast. The simulation, however, fails to capture enhanced growth over the western part of the Atlantic and the Caribbean Sea.

We summarize that the storm-resolving simulations are able to realistically reproduce the observed monthly average scaling behavior of deep convective cloud cells across a broad range of spatial scales. Major simulation deficits are identified for marine convection cells with diameters larger than $100 \mathrm{~km}$. These cells are underrepresented, and their absence introduces significant biases in cold cloud coverage. The causes of these model biases are still not well understood. Simulated convection over land is better represented than its marine counterpart, possibly due to its stronger coupling to the diurnally heated boundary layer. These and other temporal effects are further discussed in the next section.

\section{b. Temporal variability of deep convective clouds}

Tropical convection exhibits regular variations on subdaily as well as multiday time scales (see, e.g., Duvel 1989, 1990). The latter especially is influenced by the impact of equatorial waves that strongly modulate convective activity over the tropical Atlantic [see
Kiladis et al. (2009) for a general overview]. To investigate the temporal variability of simulated cold cloud characteristics in relation to the observation, we apply a variance decomposition technique similar to Rempel et al. (2017). In a first step, daily average values are calculated and subtracted from the considered time series: for instance, the relative occurrence of BT10.8 values in a certain bin interval. The resulting time series is thus corrected for the multiday variability. In a second step, values at the same local time are gathered, and an average diurnal cycle is calculated. This average diurnal cycle is again subtracted from the signal to obtain a time series representing only the residual variance. Thus, long-term variability goes into the multiday signal, highfrequency variability contributes to the residual signal with the average diurnal behavior handled separately.

The multiday, the average diurnal, and the residual variance exactly add up to the total variance of the considered time series. After dividing by the total variance, we get a simple variance decomposition into three contributions that together add up to $100 \%$. This variance decomposition is shown in Fig. 9 for BT10.8 and BT6.2 occurrence frequencies. In general, the temporal variability of BT10.8 distributions is well represented. The range between 295 and $310 \mathrm{~K}$, mainly associated with land surface temperatures, is dominated by an average diurnal signal that accounts for around $90 \%$ of the total variability. This is first caused by the diurnal change in land surface temperatures due to solar heating, and second due to the diurnal cycle in cloud coverage, which reduces the surface contributions seen from space. In the broad range between 200 and $280 \mathrm{~K}$, the multiday 


\section{Variance decomposition of BT occurrence frequencies}

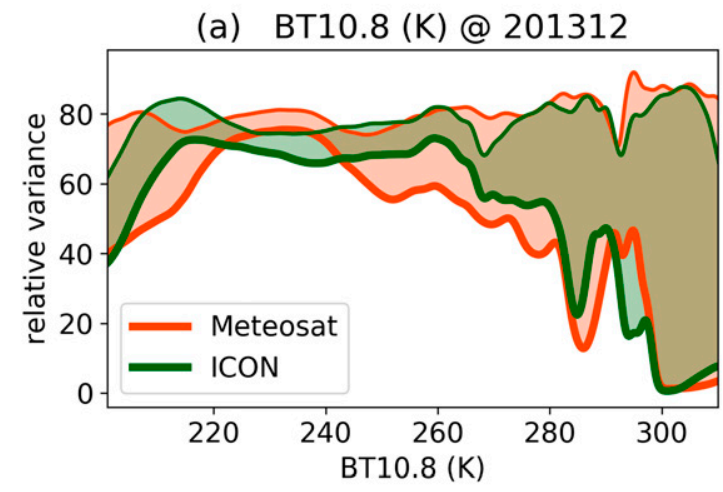

(c) BT10.8 (K) @ 201608

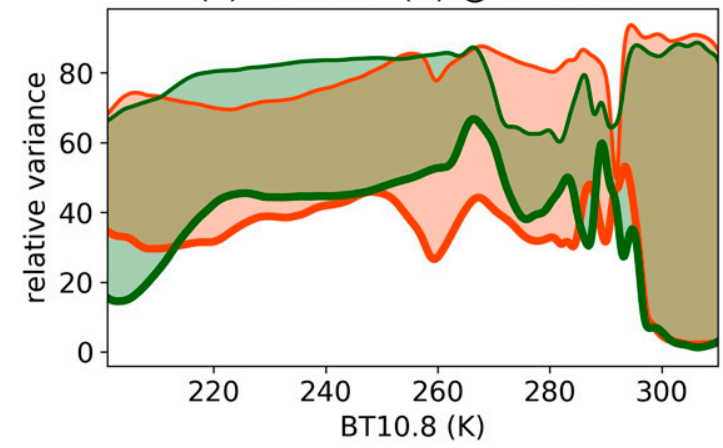

(b) BT6.2 (K) @ 201312

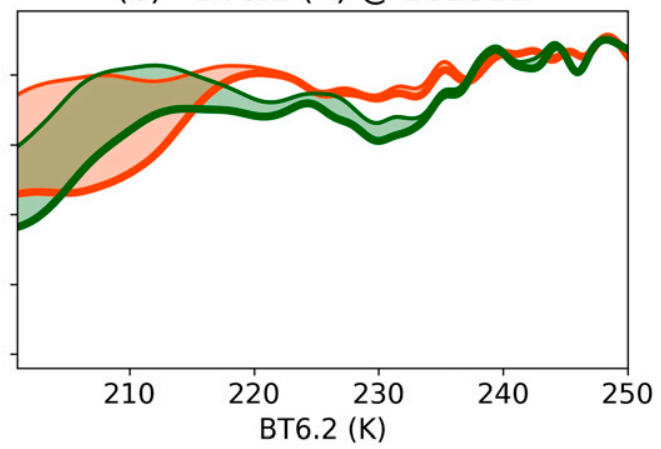

(d) BT6.2 (K) @ 201608

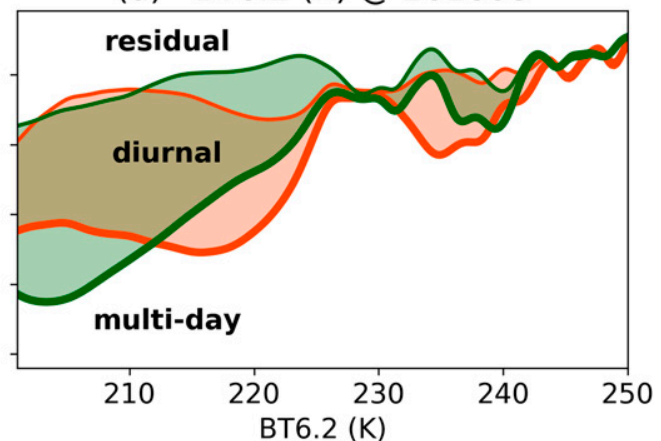

FIG. 9. As in Fig. 4, but for relative variance in the occurrence frequencies. The temporal variance in each histogram bin has been decomposed into multiday, average diurnal, and residual variance contributions. The thick solid lines represent the relative contribution of multiday variance to total variance in percent. The shaded interval adds the relative contribution of the average diurnal variance to the multiday variance; the upper thin line, thus, represents the sum of the two. The part above the thinner line can be attributed to the remaining residual variance. All three contributions together add up to $100 \%$.

variability of BT10.8 is significantly higher in December, with on average $50 \%$, compared to $30 \%$ in the summer season (see Fig. 9a vs 9c). The ICON simulation seems to have a tendency to overestimate multiday variability of cold cloud-affected BTs and correspondingly underestimates the average diurnal variability. High BT6.2s that are mainly associated with large-scale dry air patterns are dominated by multiday variability on the order of $80 \%$, which is reasonably represented in the simulations. Cloud-affected low BT6.2s show an increased diurnal signal.

In addition, Fig. 10 shows the relative variance partitioning for the observed and simulated CNSD for several size bins. In general, the contribution of multiday variability decreases with increasing cloud cell size. This behavior seems to be counterintuitive at first. It is, however, physically plausible that the number of small cells is dependent on the large-scale variability of the environmental conditions and shows a more passive response to changes in the background convective forcing. Larger convective systems possess a higher degree of organization. We hypothesize that the more involved environmental feedbacks of these cloud clusters make them less sensitive to changes in the convective forcing, giving them a higher degree of independence from multiday changes in environmental conditions. In the winter season, the multiday variability decreases from around $50 \%$ for the smallest cells to $20 \%$ for the largest cells. The contribution of the observed average diurnal variability is negligible for the winter season and for the ocean in the summer season as well. During summer and over land, the average diurnal signal increases with decreasing cell size. Up to $40 \%$ of diurnal variance relative to the total variance is observed for the smallest cells. The simulated variability of cell-size occurrence frequency matches quite well for winter and the tropical Atlantic region. For the summer ocean and the winter land, the multiday variability of small cells is overestimated. For the largest cell sizes, all simulations show a tendency to underestimate the multiday variability. 


\section{Variance decomposition of Cloud Number Size Distribution}

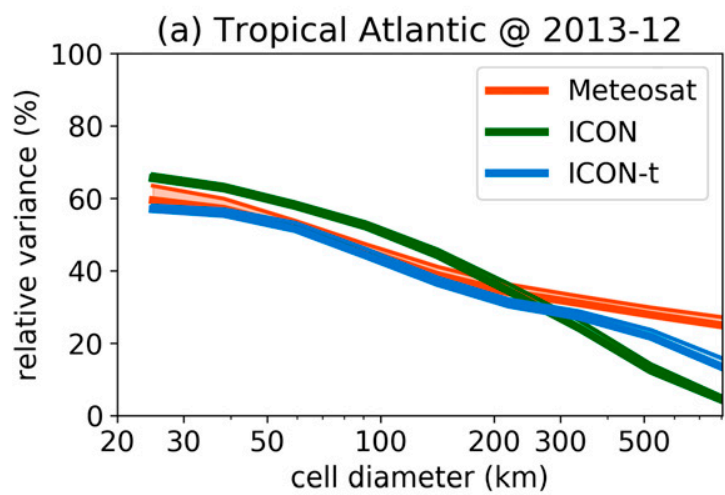

(c) Africa @ 2013-12

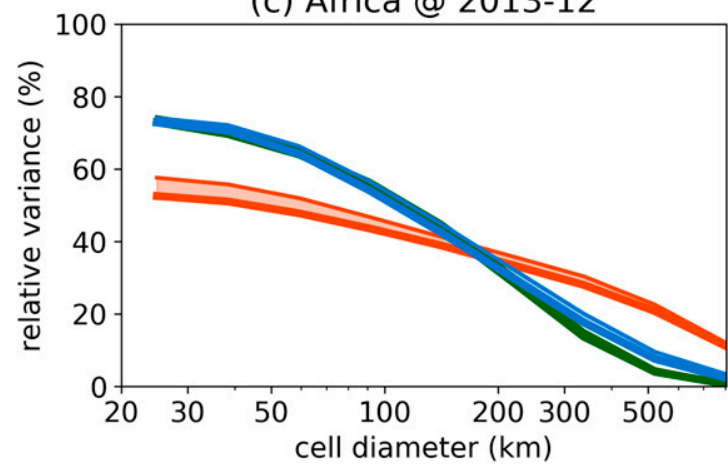

(b) Tropical Atlantic @ 2016-08

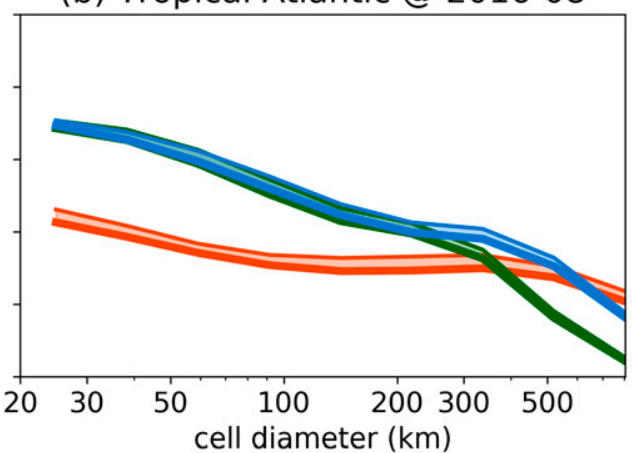

(d) Africa @ 2016-08

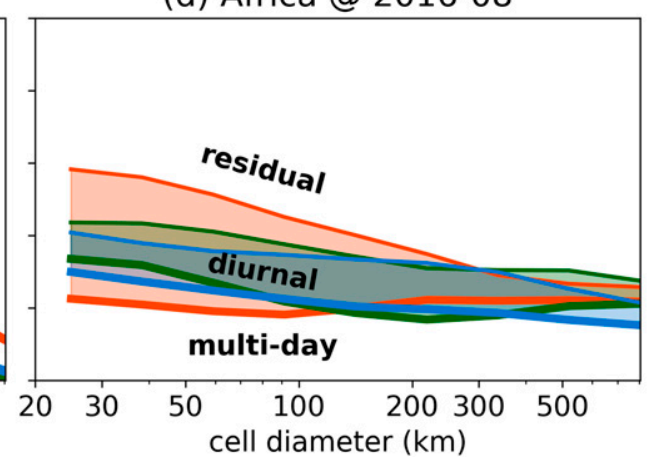

FIG. 10. As in Fig. 9, but for variance decomposition of the cloud number size distribution. Relative variance parts are shown for Meteosat (orange), ICON (green), and bias-corrected ICON-t (blue) for the (a),(b) tropical Atlantic and (c),(d) Africa for (left) December 2013, and (right) August 2016.

This indicates missing persistence and reamplification of the large mesoscale convective systems under certain conditions. Over land and during the summer season, the influence of the average diurnal variability of smalland medium-size cells up to $200 \mathrm{~km}$ is underestimated. The simulations significantly overestimate the effect of residual variability of these cloud cells, which means that observed temporal fluctuations of cell occurrence rates are relatively smaller and are more driven by external forcing mechanisms than suggested by the simulation.

The temporal evolution of cold cloud cover with BT10.8 $<230 \mathrm{~K}$ is shown in Fig. 11 for the two considered seasons as a function of local solar time (LST). The local time was calculated with respect to the model initialization time, also allowing for relative times greater than $24 \mathrm{~h}$. Furthermore, the first $12 \mathrm{~h}$ of model spinup were not excluded from this analysis; however, they were also not mixed with the last $12 \mathrm{~h}$ of simulation from the previous day runs to get a clear indication of how model spinup influences the simulated diurnal cycle. Observed cloud cover over the ocean has a double-peak structure, with the first peak at 0600 LST and the second at 1300 LST. Thereafter, observed cloud cover decays, reaching a minimum around 2000 LST. This behavior can be observed in summer as well as in winter, with a more pronounced early-afternoon peak and slightly larger average cloud coverage in winter. After spinup, the simulations approach a similar marine double-peak structure in the diurnal cloud cover variation, slightly more visible in the summer season. The early-afternoon peak is shifted by $4 \mathrm{~h}$; the timing of the early-morning peak, however, is realistically simulated. The overall amplitude of the diurnal variation of cold cloud cover over the ocean is underestimated. Over land, the observed summertime cold cloud cover shows a pronounced diurnal cycle, with a minimum of $3 \%$ around 1100 LST and a cloud cover maximum of $9 \%$ around 1800 LST. The simulation also shows a strong diurnal signal, but with a broad peak delayed around $6 \mathrm{~h}$. Considerable spinup effects are visible in the beginning of the simulation that might be one cause of the shifted diurnal peak in cloud coverage.

To link the average diurnal cycle to the different cloud sizes, we focus now on the contributions of different cloud sizes to the double-peak structure in the diurnal cycle of marine cold cloud coverage. We use anomalies 


\section{Diurnal Cycle of Cold Cloud Cover}

(a) Tropical Atlantic

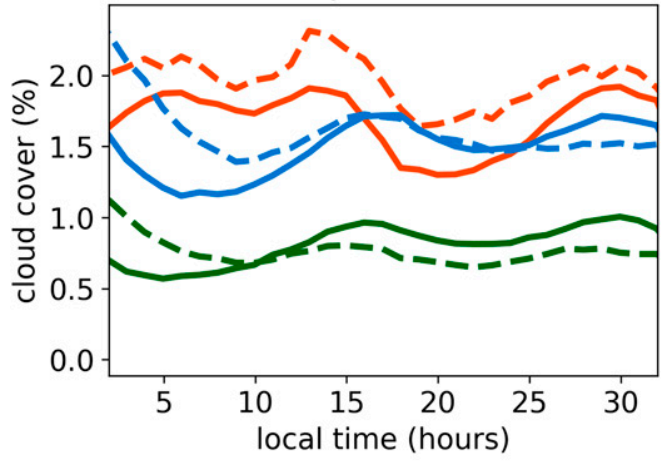

(b) Africa

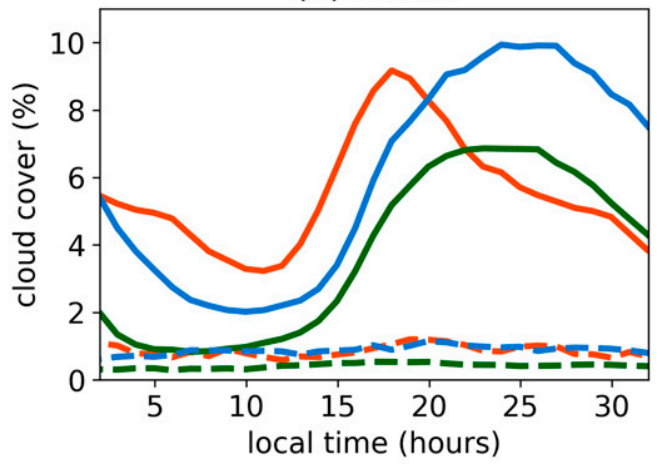

- - ICON-t @ 2013-12

FIG. 11. Diurnal cycle of cold cloud cover from BT10.8 $<230 \mathrm{~K}$ (a) over the ocean and (b) over the African continent. Cloud coverage contributions have been assembled and averaged for local solar times relative to the model initiation time of 0000 UTC, allowing for times greater than $24 \mathrm{~h}$. Averages for the winter season (dashed lines) are shown together with summer season values (solid lines). Note the different vertical axis ranges in the two panels.

of CCDFs, which are presented in Fig. 12. This metric shares some similarities with the score statistic presented by Pearson et al. (2010, 2014), which is based on the normalized CNSD time series. At the time of the earlymorning peak, observed CCDF anomalies are positive around a cell size of $200 \mathrm{~km}$. Subsequent spatial growth (indicated by the inclined red band in Fig. 12) leads to high CCDF anomalies around 500-km cell diameter in the early afternoon. In the evening hours, possibly after sunset, CCDF anomalies start to decay across a range from $100-$ to $800-\mathrm{km}$ scale. The observed decay is more pronounced for the cell diameters larger than $300 \mathrm{~km}$, which gives the chance for the medium-range cells around $200 \mathrm{~km}$ to quickly reamplify in the early-morning hours. This observed size partitioning of diurnal cloud coverage compares well with results from Machado et al. (1993), who investigated the effect of diurnal variations on cold cloud coverage based on early Meteosat observations. The simulations hardly reproduce the observed features of the CCDF anomalies. Model spinup is again dominant in the morning hours up to 1000 LST, leading to a positive anomaly (due to too-persistent initial cloud features) in the wintertime simulations and a negative anomaly in summer (due to strong decay of initial clouds and slow buildup again). This illustrates that the details of the model spinup behavior are highly dependent on the environmental conditions. The summertime simulations show a promising diurnal pattern after spinup, especially clear in ICON-t. The simulated afternoon peak (now shifted to the evening) mainly results from the variation of large cells around $500 \mathrm{~km}$, whereas the simulated early-morning peak is predominantly induced by medium-range cells around $200 \mathrm{~km}$. It remains an open question if this signal will become clearer for convection-resolving simulations performed with longer lead times.

Depending on the season, the multiday variability in the tropical Atlantic is dominated either by oscillations with a frequency of around 2 weeks or westward-propagating waves with a much more frequent reoccurrence. The different modes of multiday variability are visualized in Fig. 13, which combine relative occurrence frequency of cold clouds (under the condition of BT10.8 $<230 \mathrm{~K}$ ) and upper-tropospheric dry air patches (under the condition of BT6.2> $245 \mathrm{~K}$ ) averaged over the latitude band from $0^{\circ}$ to $15^{\circ} \mathrm{N}$. In the winter season, an oscillation with spatial scales of $30^{\circ}-40^{\circ}$ longitude (i.e., several thousand kilometers) and 10-16-day period is superposed by a large-scale westward-propagating wave. The propagating wave is more pronounced in the cloud frequency field, and its phase progression is on the order of $4^{\circ}$ day $^{-1}$, corresponding to $400-500 \mathrm{~km} \mathrm{day}^{-1}$. The simulations capture the large-scale structure in the wave patterns in upper-tropospheric water vapor and cold cloud coverage. The relative coverage of cold cloud areas is, however, significantly underestimated, leading to fewer convectively active regions. In the summer season, dry disturbances propagate across the whole 

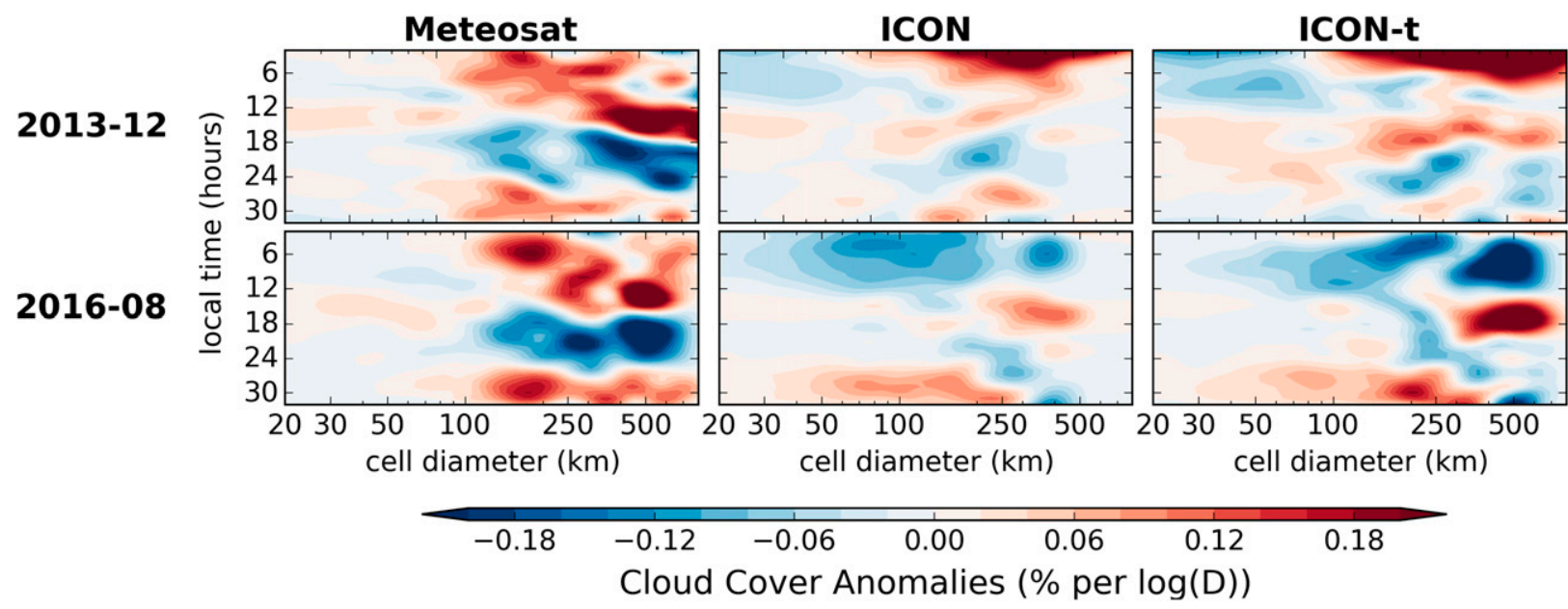

FIG. 12. Anomalies of CCDFs as a function of cell diameter and local solar time over the tropical Atlantic. CCDFs have been normalized with respect to the $\ln (D)$ (similar to Fig. 5b), and CCDF anomalies have been calculated by subtracting the time-average CCDF. Compared are (left) Meteosat observations, (middle) ICON simulations, and (right) bias-corrected ICON-t for (top) December 2013 and (bottom) August 2016.

tropical Atlantic, with a reoccurrence frequency of 5-7 days and a phase progression speed of $8^{\circ}-10^{\circ}$ day $^{-1}$, corresponding to around $1000 \mathrm{~km}$ day $^{-1}$. Alternating with the dry air disturbances, small bands of cold cloudiness propagate with similar speed toward the west. The summer season simulations capture several of the observed features. In particular, simulated cloud bands show a similar progression speed and temporal persistence. The simulated duration of cold cloud events at a certain longitude position is, however, slightly overestimated, with median values increasing from $5 \mathrm{~h}$ for observation to $6 \mathrm{~h}$ for bias-corrected simulation. Summarizing, the simulations are, in general, very well suited for the representation of typical patterns of multiday variability of cold cloudiness and upper-tropospheric water vapor.

In summary, we see that a size-resolved analysis helps to improve the understanding the temporal variability of simulated tropical convection. We could identify that the number of larger cloud cells is less affected by multiday variability, possibly due to stronger feedbacks shaping their own environmental conditions. We further showed that the observed double peak in the diurnal cycle of marine cloud coverage might be caused by subsequent spatial growth, a process that still needs to be improved in the simulations.

\section{Conclusions and outlook}

Deep moist convection in the tropics is an important component of the climate system. Deep convective clouds and their accompanying cirrus anvil shields strongly influence the radiative energy balance in the tropics. Realistic simulation of tropical dynamics with numerical models is, however, inherently difficult. Convective-scale processes need to be resolved over large domains in which convective-scale elements then have the chance to organize into large-scale structures.

The goal of the current study is to provide a thorough analysis of observed and simulated characteristics of deep convective clouds over the tropical Atlantic and neighboring continents. We aim to assess realism and possible shortcomings of large-extent, storm-resolving simulations, which have been performed with a grid spacing of $2.4 \mathrm{~km}$. Special emphasis is put on the comparison of convective activity and size-related cell properties, contrasting two different seasons: boreal summer and winter. The simulations are evaluated against infrared Meteosat observations, which have a comparable spatial resolution. A satellite forward operator is applied to the simulation output to assess the model's performance in observation space. Furthermore, we introduce a histogram matching technique to analyze similarities and differences in the representation of spatial structures separated from the analysis of BT histograms. The former are assessed based on transformed simulation fields that basically include information about the rank of individual data points. These fields are decomposed into individual cells with the help of a threshold-based segmentation technique, and a set of object-based metrics is analyzed. Based thereon, we obtain the following conclusions:

(i) The simulations are able to establish a well-defined ITCZ region over the tropical Atlantic, being closer to the observation in summer than in winter. Furthermore, 


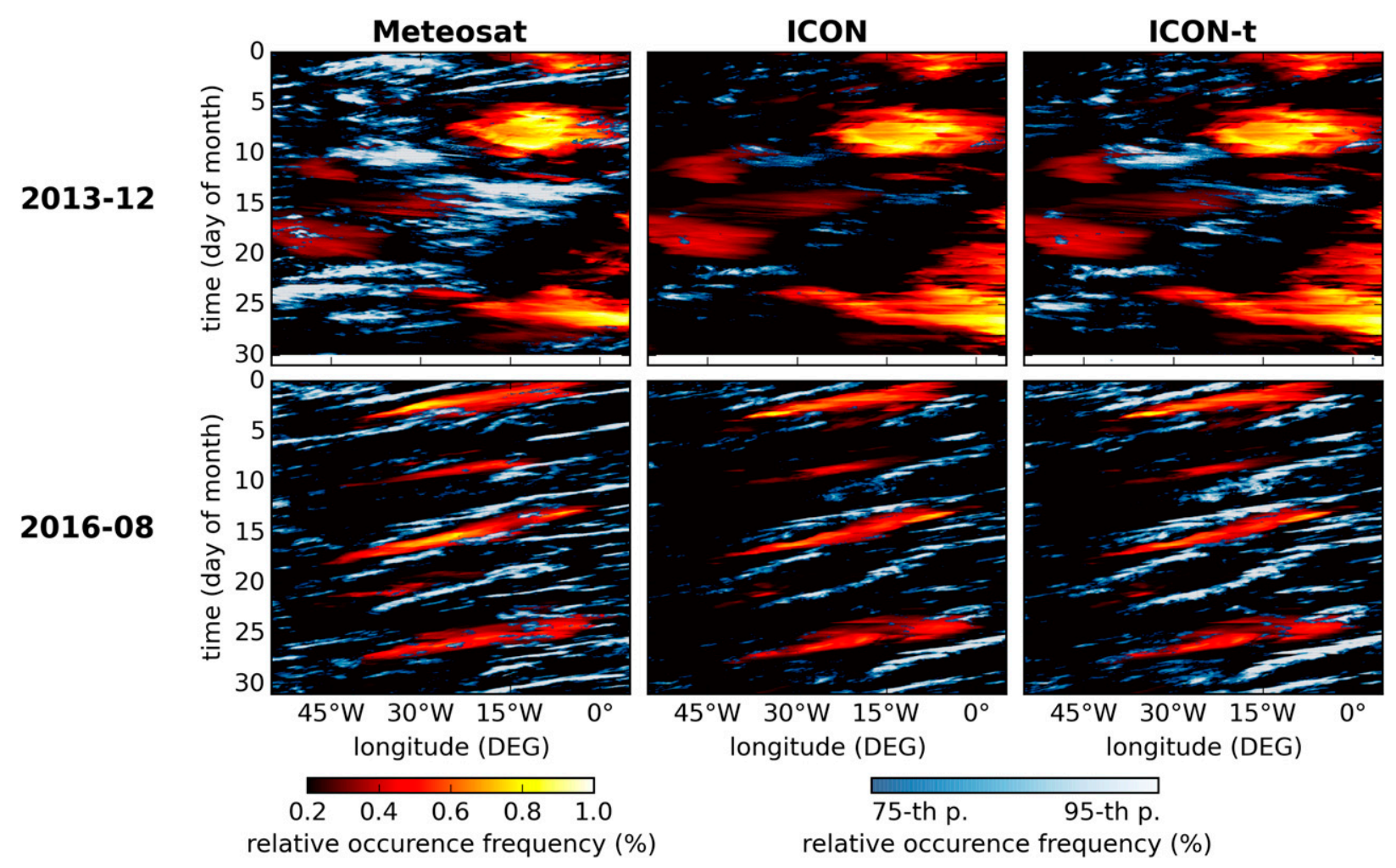

FIG. 13. Relative frequency of occurrence of deep clouds (BT10.8 $<230 \mathrm{~K}$; blue shades) and dry air patches with (BT6.2 $>245 \mathrm{~K}$; yellow-red shades) as a function of longitude and time (Hovmoeller diagram). Data from (left) Meteosat, (middle) ICON, and (right) ICON-t for the (top) winter and (bottom) summer seasons. The color range of deep cloud occurrence rates is scaled to meet the 75 th- to 95th-percentile range of the observation.

convective activity developing over the land seems to be better represented than its marine counterpart.

(ii) The observed, as well as simulated, CNSDs show a power law behavior, with negative slopes between 2.1 and 2.6 for the observation and between 2.2 and 3.3 for simulations. Observed slopes are typically steeper in winter than in summer; for summer, steeper slopes are observed over the ocean than over the land. Simulated slopes, in general, reproduce the seasonal and land-ocean differences in the average CNSDs. The simulated slopes are, however, too steep, indicating too many small and too few very large tropical cloud cells.

(iii) The observed cold cloud cover distribution is found to be dominated by cells larger than $100 \mathrm{~km}$. The underrepresentation of these scales in the simulation introduces a significant bias up to a factor of 2 , with this bias being more pronounced over the ocean. The average observed diurnal variation in cloud coverage shows a double-peak behavior over the ocean with maxima at 0600 and 1300 LST, which is caused by an upscale growth of marine cloud cells between 100 and $400 \mathrm{~km}$. The simulations capture the diurnal cloud coverage evolution qualitatively, however, with too-small diurnal amplitude, with major peaks delayed and with a less clear growth signature across the spatial scales.

(iv) Considering temporal variability in general, we see that several interdaily modes, from westwardpropagating waves to biweekly oscillations, are well reproduced by the current simulation setup. We further recognize that the number of large cloud cells is less affected by multiday variability. This is found in observations, as well as in simulations, and might be related to longer lifetimes of large cloud cells and to the larger dynamical feedbacks these cells induce to modify their own environmental conditions.

We like to emphasize that the discussed simulations are the first in a series of planned experiments of stormresolving simulations over the tropics. They have never been optimized as is normally done for climate and weather models (Hourdin et al. 2017). Considering this aspect, the realism of tropical Atlantic simulation goes far beyond our initial expectations. The satellite-based evaluation focused on a very specific part of the tropical system, mainly the structure of very cold cloud patches (colder than $230 \mathrm{~K}$ ), which only makes up a small 
percentage of the total cloud cover. As a result of the analysis, we could identify major shortcomings in the representation of the largest organized convective systems over the ocean, especially in boreal winter situations. The origins of these limitations need to be further understood. Possible explanations might be the too-short run times of the model before reinitialization and the missing feedbacks with the underlying ocean surface (see Klocke et al. 2017). Corresponding experiments are planned, and a repeated examination of the evaluation analysis will help to assess the impact of different factors and thus hopefully increase our capabilities for more realistic simulations of tropical convection. Further sensitivity experiments will be targeted on the tuning of microphysical parameters, the consistent coupling between radiation and microphysics (with special emphasis on anvil radiative properties), and marine boundary layer processes. In addition, improving the representation of low-level cloud processes will be the focus of targeted sensitivity experiments, in which conventional and advanced methods for the parameterization of shallow convection will be contrasted with explicit simulations and observations.

New computer and numerical methods allow us to use complex atmospheric models at resolutions to explicitly resolve parts of the model physics over large domains that were formerly part of subgrid-scale parameterizations. Even global simulations at storm-resolving scales are soon becoming feasible. At the same time, satellite observations are available, which allow targeted evaluation of variability and structure of deep convection. With the two in tandem, we feel well equipped to contribute to the development and improvement of the future atmospheric models for weather and climate.

Acknowledgments. FS and MB acknowledge funding within the High Definition Clouds and Precipitation for advancing Climate Prediction $\left[\mathrm{HD}(\mathrm{CP})^{2}\right]$ project funded by the BMBF (German Ministry for Education and Research) under respective Grants 01LK1507C and 01LK1501B. DK is supported by the Hans Ertel Center for Weather Research (HErZ), a German research network of universities, research institutions, and DWD, which is funded by the BMVI (Federal Ministry of Transport and Digital Infrastructure). We thank EUMETSAT for providing SEVIRI data. We thank our colleagues Vasilis Barlakas, Hartwig Deneke, Karsten Peters, and Aiko Voigt and three anonymous reviewers for their helpful comments on earlier versions of the manuscript. Concerning data availability: the simulation data used in this study are stored on the supercomputer of the German Climate Computing Center (DKRZ) and can be made available from the authors upon request. The observation data are licensed by EUMETSAT and have to be requested there.

\section{APPENDIX A}

\section{Details about the Segmentation Technique}

In the following, the details of the applied segmentation method are described. The procedure sequentially performs five steps to come from the initial BT10.8 field to a categorical field of object labels (see Fig. A1). As discussed by, for example, Davis et al. (2006) and Weniger and Friederichs (2016), spatial filtering is an important part of an object-based analysis and results in greater robustness against random field variations. Therefore, the BT10.8 field is smoothed with a curvature flow filter (Malladi and Sethian 1995) in the first step (from Fig. A1a to Fig. A1b). The filter method is typically used for image denoising and has the advantage that sharp boundaries of features (in our case, clouds) are preserved. The chosen filter parameters are 0.05 for the nondimensional time step and 5 for the number of iterations. In the second step, a threshold value of $230 \mathrm{~K}$ is applied to the smoothed BT10.8 field, and all values smaller than this threshold are considered as potential cold cloud cells (see Fig. A1c). In the third step, so-called markers are placed as initial positions for region growing. These markers are found by an iterative shrinking procedure. To achieve this, first-guess objects are derived by a standard four-connected compound analysis that identifies contiguous cell areas only connected across the gridbox edges. For each grid point within the object, we determine the Euclidean distance to the closest background (outside the object) position. This absolute distance field is normalized by the maximum distance per object yielding a relative distance field, which is 1 at the core of the object and decays to zero toward the object edges. Thereafter, we shrink the objects by $10 \%$ of their size by basically applying a threshold of 0.1 to the relative distance field. The shrinking sequence is repeated three times, and the resulting set of object points (see Fig. A1d) is taken as marker input for step four in Fig. A1. This implementation of the marker method has the advantage that it behaves scale invariant, meaning that it splits objects of similar shapes independently of their spatial scale. Watershed segmentation is applied in step four that can be easily understood if one imagines a mountainous landscape in which the mountain valleys are slowly filled with colored water. Disjoint valleys get a different color, and each color is representing a label of an object. If now the water level rises, the water-filled areas start to grow. If the water bodies of different valleys with different colors touch, a dam is built at the interface to separate these different water bodies. The method stops when a predefined water level is reached, which is, in our case, the threshold value of $230 \mathrm{~K}$. In the final step five, we 


\section{Segmentation Procedure}

(a) Start: BT10.8-Field

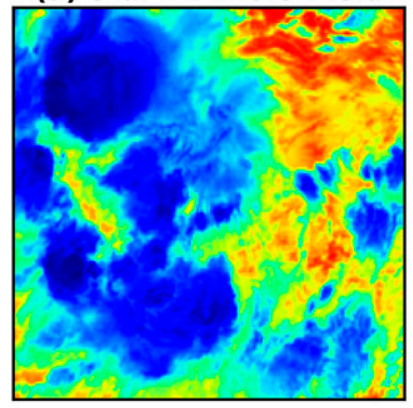

(b) Curvature Smoothing

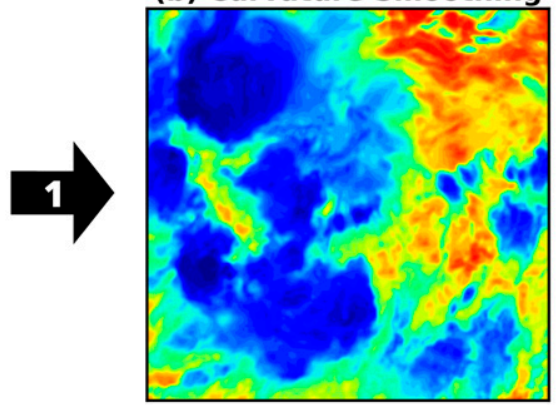

Iterations: 5

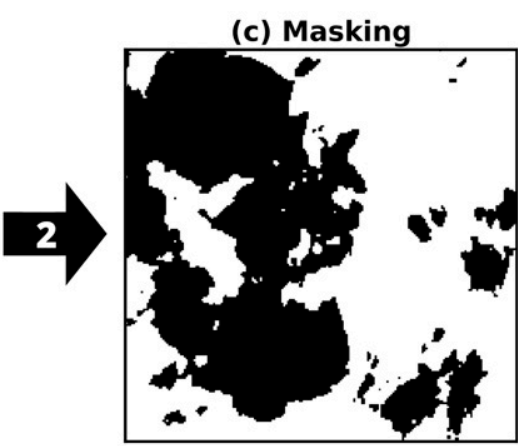

Threshold: $230 \mathrm{~K}$

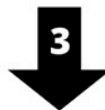

(d) Determine Marker Positions

(e) Watershed Segmentation

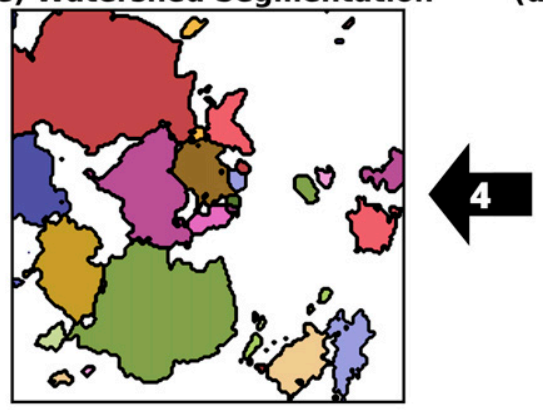

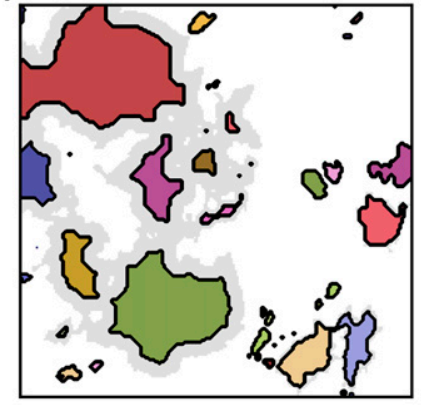

Iterations: 3, Reduction: 10\%

FIG. A1. Schematic depiction of the applied segmentation procedure based on a cutout of the BT10.8 field from Fig. 2. From (a) the starting point to (f) the final result, the segmentation algorithm sequentially runs through five steps (black arrows) in clockwise direction. The BT10.8 field shown in (a) is smoothed with a curvature flow filter (step 1) using five iterations and then masked with a threshold value of $230 \mathrm{~K}$ (step 2). The interior is shown in black. Marker objects are determined in step 3 via a method that iteratively shrinks first-guess objects for $10 \%$ of their size (three iterations). The marker objects are shown in colors, and gray shading visualizes the edges, which have been removed. Based on the marker field, watershed segmentation is applied in step 4, which basically fills up the gray areas with the color of the nearest marker. Finally, objects are merged again that share an interface having a distance to background, which is at least $50 \%$ of the maximum distance-to-background values of one of the objects, which belong to the interface (see text for further explanation). From (d) to (e), colors of the largest objects are passed.

merge again all cells that share a long connecting interface in which the combined object cluster essentially looks cut through in the middle. The condition for the merge is also based on the distance-to-background field. If the absolute distance along the interface is larger than $50 \%$ of the maximum distance in one of the individual cells, a merge is applied to all involved cells. In addition, a second filter step is applied to the merged data in step five. All cells that have connected areas smaller than 40 model grid boxes are disregarded. The chosen cutoff corresponds to an equivalent diameter around $17 \mathrm{~km}$, which is 7 times the native grid spacing and, thus, just beyond the effective model resolution (see, e.g., Zängl et al. 2015).
In the applied object-based analysis, we only consider cloud cells that are located well inside the domain and remove any cell that is closer than 11 grid points to the domain edge.

\section{APPENDIX B}

\section{Calculation of Instantaneous Object Area Rates}

In the following, the derivation of instantaneous temporal trends of object areas that will be used to distinguish between active and dissipating cold cloud cells is discussed. As the cell objects possess significant 
horizontal motion within the simulation output interval $(\Delta t)$ of $1 \mathrm{~h}$, we apply an extrapolation technique to correct for potential location mismatches due to advection. Therefore, the flow field is estimated from the sequential evolution of observed as well as simulated BT10.8 fields using an optical flow technique [OpenCV implementation of Farnebäck (2003)]. In essence, the method tries to find structures at the actual time step $t$ that have been identified at previous time step $t-\Delta t$. These structures are compared at different coarse-graining levels building a pyramid from finer to coarser scales. A search window (in our case, $11 \times 11$ grid points, roughly $30 \times$ $30 \mathrm{~km}^{2}$ in native resolution) is shifted, and the location is identified where the absolute difference between the target and the shifted window is minimal. As a result, the applied optical flow algorithm calculates a dense two-dimensional field of location shifts, which are projected onto the segmented objects and finally averaged. To get rid of surface contributions, BT10.8 values larger than $260 \mathrm{~K}$ have been replaced by this threshold. Furthermore, the input BT fields are spatially subsampled by a factor of 4 for increasing efficiency (i.e., only every fourth grid point has been used for computations).

In the next steps, the segmented objects at $t-\Delta t$ are shifted by their average flow, and the resulting field is combined with the unaltered segmentation result at $t$ to build a three-dimensional data stack, adding the time coordinate as third dimension to the existing two horizontal dimensions $(x, y)$. The 3D data are segmented again with the same parameter options as their twodimensional counterpart (see appendix A). The resulting objects are three-dimensional where the time dimension is composed of two layers. Objects that are connected at two subsequent times are labeled with the same index. Areas with equal index are summed separately for the two times, and the difference between the two divided by the time interval of $1 \mathrm{~h}$ gives the object area rate. The morphology of the three-dimensional objects can be quite complex, including multiple splits and merges where the areas of all involved cells are counted.

\section{REFERENCES}

Arakawa, A., 2004: The cumulus parameterization problem: Past, present, and future. J. Climate, 17, 2493-2525, https://doi.org/ 10.1175/1520-0442(2004)017<2493:RATCPP>2.0.CO;2.

- , and J.-H. Jung, 2011: Multiscale modeling of the moistconvective atmosphere-A review. Atmos. Res., 102, 263-285, https://doi.org/10.1016/j.atmosres.2011.08.009.

Bechtold, P., I. Sandu, D. Klocke, N. Semane, M. Alhgrimm, A. Beljaars, R. Forbes, and M. Rodwell, 2014a: The role of shallow convection in ECMWF's integrated forecasting system. ECMWF Tech. Memo. 725, 27 pp., https://www.ecmwf. int/sites/default/files/elibrary/2014/8016-role-shallow-convection-ecmwfs-integrated-forecasting-system.pdf.
— N. Semane, P. Lopez, J.-P. Chaboureau, A. Beljaars, and N. Bormann, 2014b: Representing equilibrium and nonequilibrium convection in large-scale models. J. Atmos. Sci., 71, 734-753, https://doi.org/10.1175/JAS-D-13-0163.1.

Bennartz, R., and M. Schroeder, 2012: Convective activity over Africa and the tropical Atlantic inferred from 20 years of geostationary Meteosat infrared observations. J. Climate, $\mathbf{2 5}$ 156-169, https://doi.org/10.1175/2011JCLI3984.1.

Birch, C. E., J. H. Marsham, D. J. Parker, and C. M. Taylor, 2014: The scale dependence and structure of convergence fields preceding the initiation of deep convection. Geophys. Res. Lett., 41, 4769-4776, https://doi.org/10.1002/2014GL060493.

Bony, S., B. Stevens, D. Coppin, T. Becker, K. A. Reed, A. Voigt, and B. Medeiros, 2016: Thermodynamic control of anvil cloud amount. Proc. Natl. Acad. Sci. USA, 113, 8927-8932, https:// doi.org/10.1073/pnas.1601472113.

Brueck, M., L. Nuijens, and B. Stevens, 2015: On the seasonal and synoptic time-scale variability of the North Atlantic trade wind region and its low-level clouds. J. Atmos. Sci., 72, 14281446, https://doi.org/10.1175/JAS-D-14-0054.1.

Chaboureau, J.-P., and J.-P. Pinty, 2006: Validation of a cirrus parameterization with Meteosat second generation observations. Geophys. Res. Lett., 33, L03815, https://doi.org/10.1029/ 2005 GL024725.

_ J.-P. Cammas, P. Mascart, J.-P. Pinty, C. Claud, R. Roca, and J.-J. Morcrette, 2000: Evaluation of a cloud system life-cycle simulated by the Meso-NH model during FASTEX using METEOSAT radiances and TOVS-3I cloud retrievals. Quart. J. Roy. Meteor. Soc., 126, 1735-1750, https://doi.org/10.1256/smsqj.56609.

Chevallier, F., and G. Kelly, 2002: Model clouds as seen from space: Comparison with geostationary imagery in the $11-\mu \mathrm{m}$ window channel. Mon. Wea. Rev., 130, 712-722, https://doi.org/ 10.1175/1520-0493(2002)130<0712:MCASFS > 2.0.CO;2.

Davis, C., B. Brown, and R. Bullock, 2006: Object-based verification of precipitation forecasts. Part I: Methodology and application to mesoscale rain areas. Mon. Wea. Rev., 134, 1772-1784, https:// doi.org/10.1175/MWR3145.1.

Duvel, J. P., 1989: Convection over tropical Africa and the Atlantic Ocean during northern summer. Part I: Interannual and diurnal variations. Mon. Wea. Rev., 117, 2782-2799, https://doi.org/ 10.1175/1520-0493(1989)117<2782:COTAAT>2.0.CO;2.

- 1990: Convection over tropical Africa and the Atlantic Ocean during northern summer. Part II: Modulation by easterly waves. Mon. Wea. Rev., 118, 1855-1868, https://doi.org/ 10.1175/1520-0493(1990)118<1855:COTAAT>2.0.CO;2.

Ebert, E. E., 2008: Fuzzy verification of high-resolution gridded forecasts: A review and proposed framework. Meteor. Appl., 15, 51-64, https://doi.org/10.1002/met.25.

Farnebäck, G., 2003: Two-frame motion estimation based on polynomial expansion. Proc. Scandinavian Conf. on Image Analysis, J. Bigun and T. Gustavsson, Eds., Lecture Notes in Computer Science, Vol. 2749, Springer, 363-370, https://doi.org/10.1007/ 3-540-45103-X_50.

Gettelman, A., J. Kay, and K. Shell, 2012: The evolution of climate sensitivity and climate feedbacks in the Community Atmosphere Model. J. Climate, 25, 1453-1469, https://doi.org/10.1175/ JCLI-D-11-00197.1.

Gilleland, E., D. Ahijevych, B. G. Brown, B. Casati, and E. E. Ebert, 2009: Intercomparison of spatial forecast verification methods. Wea. Forecasting, 24, 1416-1430, https://doi.org/10.1175/ 2009WAF2222269.1.

Grabowski, W. W., 2001: Coupling cloud processes with the large-scale dynamics using the Cloud-Resolving Convection Parameterization 
(CRCP). J. Atmos. Sci., 58, 978-997, https://doi.org/ 10.1175/1520-0469(2001)058<0978:CCPWTL > 2.0.CO;2.

Holloway, C. E., A. A. Wing, S. Bony, C. Muller, H. Masunaga, T. S. L'Ecuyer, D. D. Turner, and P. Zuidema, 2017: Observing convective aggregation. Surv. Geophys., 38, 11991236, https://doi.org/10.1007/s10712-017-9419-1.

Hourdin, F., and Coauthors, 2017: The art and science of climate model tuning. Bull. Amer. Meteor. Soc., 98, 589-602, https:// doi.org/10.1175/BAMS-D-15-00135.1.

Inoue, T., M. Satoh, H. Miura, and B. Mapes, 2008: Characteristics of cloud size of deep convection simulated by a global cloud resolving model over the western tropical Pacific. J. Meteor. Soc. Japan, 86A, 1-15, https://doi.org/10.2151/jmsj.86A.1.

Keil, C., A. Tafferner, and T. Reinhardt, 2006: Synthetic satellite imagery in the Lokal-Modell. Atmos. Res., 82, 19-25, https:// doi.org/10.1016/j.atmosres.2005.01.008.

Khairoutdinov, M. F., and K. Emanuel, 2013: Rotating radiativeconvective equilibrium simulated by a cloud-resolving model J. Adv. Model. Earth Syst., 5, 816-825, https://doi.org/10.1002/ 2013MS000253.

— , S. K. Krueger, C.-H. Moeng, P. A. Bogenschutz, and D. A. Randall, 2009: Large-eddy simulation of maritime deep tropical convection. J. Adv. Model. Earth Syst., 1, 15, https://doi.org/10.3894/JAMES.2009.1.15.

Kiladis, G. N., M. C. Wheeler, P. T. Haertel, K. H. Straub, and P. E. Roundy, 2009: Convectively coupled equatorial waves. Rev. Geophys., 47, RG2003, https://doi.org/10.1029/ 2008RG000266.

Klepp, C., F. Ament, S. Bakan, L. Hirsch, and B. Stevens, 2014: NARVAL campaign report. Max Planck Institute for Meteorology Tech. Rep. 164, 218 pp., www.mpimet.mpg.de/ fileadmin/publikationen/Reports/WEB_BzE_164_last.pdf.

Klocke, D., M. Brueck, C. Hohenegger, and B. Stevens, 2017: Rediscovery of the doldrums in storm-resolving simulations over tropical Atlantic. Nat. Geosci., 10, 891-896, https://doi.org/10.1038/ s41561-017-0005-4.

Kouadio, Y. K., L. A. Machado, and J. Servain, 2010: Tropical Atlantic hurricanes, easterly waves, and west African mesoscale convective systems. Adv. Meteor., 2010, 284503, https:// dx.doi.org/10.1155/2010/284503.

Li, Y., D. W. J. Thompson, G. L. Stephens, and S. Bony, 2014: A global survey of the instantaneous linkages between cloud vertical structure and large-scale climate. J. Geophys. Res. Atmos., 119, 3770-3792, https://doi.org/10.1002/2013JD020669.

Machado, L. A. T., and W. B. Rossow, 1993: Structural characteristics and radiative properties of tropical cloud clusters. Mon. Wea. Rev., 121, 3234-3260, https://doi.org/10.1175/1520-0493 (1993) $121<3234:$ SCARPO > 2.0.CO;2.

_ , and J.-P. Chaboureau, 2015: Effect of turbulence parameterization on assessment of cloud organization. Mon. Wea. Rev., 143, 3246-3262, https://doi.org/10.1175/MWR-D-14-00393.1.

_ M. Desbois, and J.-P. Duvel, 1992: Structural characteristics of deep convective systems over tropical Africa and the Atlantic Ocean. Mon. Wea. Rev., 120, 392-406, https://doi.org/10.1175/ 1520-0493(1992)120<0392:SCODCS > 2.0.CO;2.

— - J.-P. Duvel, and M. Desbois, 1993: Diurnal variations and modulation by easterly waves of the size distribution of convective cloud clusters over west Africa and the Atlantic Ocean. Mon. Wea. Rev., 121, 37-49, https://doi.org/10.1175/ 1520-0493(1993)121<0037:DVAMBE > 2.0.CO;2.

Malladi, R., and J. A. Sethian, 1995: Image processing via level set curvature flow. Proc. Natl. Acad. Sci. USA, 92, 7046-7050, https://doi.org/10.1073/pnas.92.15.7046.
Mapes, B., 2016: Gregarious convection and radiative feedbacks in idealized worlds. J. Adv. Model. Earth Syst., 8, 1029-1033, https://doi.org/10.1002/2016MS000651.

Marsham, J. H., N. S. Dixon, L. Garcia-Carreras, G. Lister, D. J. Parker, P. Knippertz, and C. E. Birch, 2013: The role of moist convection in the west African monsoon system: Insights from continental-scale convection-permitting simulations. Geophys. Res. Lett., 40, 1843-1849, https://doi.org/ 10.1002/grl.50347.

Matsui, T., and Coauthors, 2014: Introducing multisensor satellite radiance-based evaluation for regional Earth system modeling. J. Geophys. Res. Atmos., 119, 8450-8475, https://doi.org/ 10.1002/2013JD021424.

Maurer, V., N. Kalthoff, and L. Gantner, 2015: Predictability of convective precipitation for West Africa: Does the land surface influence ensemble variability as much as the atmosphere? Atmos. Res., 157, 91-107, https://doi.org/10.1016/j.atmosres.2015.01.016.

Mauritsen, T., and B. Stevens, 2015: Missing iris effect as a possible cause of muted hydrological change and high climate sensitivity in models. Nat. Geosci., 8, 346-351, https://doi.org/ 10.1038/ngeo2414.

McFarquhar, G. M., S. Iacobellis, and R. C. J. Somerville, 2003: SCM simulations of tropical ice clouds using observationally based parameterizations of microphysics. J. Climate, 16, 1643-1664, https:// doi.org/10.1175/1520-0442(2003)016<1643:SSOTIC>2.0.CO;2.

Medeiros, B., B. Stevens, I. M. Held, M. Zhao, D. L. Williamson, J. G. Olson, and C. S. Bretherton, 2008: Aquaplanets, climate sensitivity, and low clouds. J. Climate, 21, 4974-4991, https:// doi.org/10.1175/2008JCLI1995.1.

Möbis, B., and B. Stevens, 2012: Factors controlling the position of the intertropical convergence zone on an aquaplanet. $J . A d v$. Model. Earth Syst., 4, M00A04, https://doi.org/10.1029/ 2012MS000199.

Morcrette, J.-J., 1991: Evaluation of model-generated cloudiness: Satellite-observed and model-generated diurnal variability of brightness temperature. Mon. Wea. Rev., 119, 1205-1224, https://doi.org/10.1175/1520-0493(1991)119<1205: EOMGCS $>2.0 . \mathrm{CO} ; 2$.

Negri, R. G., L. A. T. Machado, S. English, and M. Forsythe, 2014: Combining a cloud-resolving model with satellite for cloud process model simulation validation. J. Appl. Meteor. Climatol., 53, 521-533, https://doi.org/10.1175/JAMC-D-12-0178.1.

Nicholson, S. E., 2013: The West African Sahel: A review of recent studies on the rainfall regime and its interannual variability. ISRN Meteor., 2013, 453521, https://dx.doi.org/10.1155/ 2013/453521.

Nolan, D. S., S. N. Tulich, and J. E. Blanco, 2016: ITCZ structure as determined by parameterized versus explicit convection in aquachannel and aquapatch simulations. J. Adv. Model. Earth Syst., 8, 425-452, https://doi.org/10.1002/2015MS000560.

Otkin, J. A., T. J. Greenwald, J. Sieglaff, and H.-L. Huang, 2009: Validation of a large-scale simulated brightness temperature dataset using SEVIRI satellite observations. J. Appl. Meteor. Climatol., 48, 1613-1626, https://doi.org/10.1175/2009JAMC2142.1.

Pearson, K. J., R. J. Hogan, R. P. Allan, G. M. S. Lister, and C. E. Holloway, 2010: Evaluation of the model representation of the evolution of convective systems using satellite observations of outgoing longwave radiation. J. Geophys. Res., 115, D20206, https://doi.org/10.1029/2010JD014265.

, G. M. S. Lister, C. E. Birch, R. P. Allan, R. J. Hogan, and S. J. Woolnough, 2014: Modelling the diurnal cycle of tropical convection across the 'grey zone.' Quart. J. Roy. Meteor. Soc., 140, 491-499, https://doi.org/10.1002/qj.2145. 
Peters, O., and J. D. Neelin, 2006: Critical phenomena in atmospheric precipitation. Nat. Phys., 2, 393-396, https://doi.org/ 10.1038/nphys314.

$\longrightarrow,-$, and S. W. Nesbitt, 2009: Mesoscale convective systems and critical clusters. J. Atmos. Sci., 66, 2913-2924, https://doi.org/ 10.1175/2008JAS2761.1.

Peters, K., T. Crueger, C. Jakob, and B. Möbis, 2017: Improved MJO-simulation in ECHAM6.3 by coupling a stochastic multicloud model to the convection scheme. J. Adv. Model. Earth Syst., 9, 193-219, https://doi.org/10.1002/2016MS000809.

Randall, D. A., 2013: Beyond deadlock. Geophys. Res. Lett., 40, 5970-5976, https://doi.org/10.1002/2013GL057998.

—, M. Khairoutdinov, A. Arakawa, and W. Grabowski, 2003: Breaking the cloud parameterization deadlock. Bull. Amer. Meteor. Soc., 84, 1547-1564, https://doi.org/10.1175/BAMS-84-11-1547.

Rempel, M., F. Senf, and H. Deneke, 2017: Object-based metrics for forecast verification of convective development with geostationary satellite data. Mon. Wea. Rev., 145, 3161-3178, https://doi.org/10.1175/MWR-D-16-0480.1.

Roca, R., L. Picon, M. Desbois, H. Le Treut, and J.-J. Morcrette, 1997: Direct comparison of Meteosat water vapor channel data and general circulation model results. Geophys. Res. Lett., 24, 147-150, https://doi.org/10.1029/96GL03923.

Roh, W., and M. Satoh, 2014: Evaluation of precipitating hydrometeor parameterizations in a single-moment bulk microphysics scheme for deep convective systems over the tropical central Pacific. J. Atmos. Sci., 71, 2654-2673, https://doi.org/10.1175/ JAS-D-13-0252.1.

Sato, T., H. Miura, M. Satoh, Y. N. Takayabu, and Y. Wang, 2009: Diurnal cycle of precipitation in the tropics simulated in a global cloud-resolving model. J. Climate, 22, 4809-4826, https://doi.org/10.1175/2009JCLI2890.1.

Saunders, R., M. Matricardi, and P. Brunel, 1999: An improved fast radiative transfer model for assimilation of satellite radiance observations. Quart. J. Roy. Meteor. Soc., 125, 1407-1425, https://doi.org/10.1002/qj.1999.49712555615.

Schlemmer, L., and C. Hohenegger, 2016: Modifications of the atmospheric moisture field as a result of cold-pool dynamics. Quart. J. Roy. Meteor. Soc., 142, 30-42, https://doi.org/10.1002/ qj. 2625.

Schröder, M., M. König, and J. Schmetz, 2009: Deep convection observed by the Spinning Enhanced Visible and Infrared Imager on board Meteosat 8: Spatial distribution and temporal evolution over Africa in summer and winter 2006. J. Geophys. Res., 114, D05109, https://doi.org/10.1029/2008JD010653.

Senf, F., and H. Deneke, 2017: Uncertainties in synthetic Meteosat SEVIRI infrared brightness temperatures in the presence of cirrus clouds and implications for evaluation of cloud microphysics. Atmos. Res., 183, 113-129, https://doi.org/10.1016/ j.atmosres.2016.08.012.

Sherwood, S. C., S. Bony, and J.-L. Dufresne, 2014: Spread in model climate sensitivity traced to atmospheric convective mixing. Nature, 505, 37-42, https://doi.org/10.1038/nature12829.

Slingo, A., K. I. Hodges, and G. J. Robinson, 2004: Simulation of the diurnal cycle in a climate model and its evaluation using data from Meteosat 7. Quart. J. Roy. Meteor. Soc., 130, 14491467, https://doi.org/10.1256/qj.03.165.

Stevens, B., and S. Bony, 2013: What are climate models missing? Science, 340, 1053-1054, https://doi.org/10.1126/ science. 1237554.

— choring investigations of clouds and circulation on the edge of the ITCZ. Bull. Amer. Meteor. Soc., 97, 787-801, https://doi.org/ 10.1175/BAMS-D-14-00247.1.

Thelen, J.-C., and J. M. Edwards, 2013: Short-wave radiances: Comparison between SEVIRI and the Unified Model. Quart. J. Roy. Meteor. Soc., 139, 1665-1679, https://doi.org/10.1002/ qj.2034.

Tian, B., B. J. Soden, and X. Wu, 2004: Diurnal cycle of convection, clouds, and water vapor in the tropical upper troposphere: Satellites versus a general circulation model. J. Geophys. Res., 109, D10101, https://doi.org/10.1029/2003JD004117.

Voigt, A., S. Bony, J.-L. Dufresne, and B. Stevens, 2014: The radiative impact of clouds on the shift of the intertropical convergence zone. Geophys. Res. Lett., 41, 4308-4315, https:// doi.org/10.1002/2014GL060354.

Weniger, M., and P. Friederichs, 2016: Using the SAL technique for spatial verification of cloud processes: A sensitivity analysis. J. Appl. Meteor. Climatol., 55, 2091-2108, https://doi.org/ 10.1175/JAMC-D-15-0311.1.

Wernli, H., M. Paulat, M. Hagen, and C. Frei, 2008: SAL-A novel quality measure for the verification of quantitative precipitation forecasts. Mon. Wea. Rev., 136, 4470-4487, https:// doi.org/10.1175/2008MWR2415.1.

White, B. A., A. M. Buchanan, C. E. Birch, P. Stier, and K. J. Pearson, 2018: Quantifying the effects of horizontal grid length and parameterized convection on the degree of convective organization using a metric of the potential for convective interaction. J. Atmos. Sci., 75, 425-450, https://doi.org/10.1175/ JAS-D-16-0307.1.

Wielicki, B. A., and R. M. Welch, 1986: Cumulus cloud properties derived using Landsat satellite data. J. Climate Appl. Meteor., 25, 261-276, https://doi.org/10.1175/1520-0450(1986)025<0261: CCPDUL $>2.0 . \mathrm{CO} ; 2$.

Wing, A. A., K. Emanuel, C. E. Holloway, and C. Muller, 2017: Convective self-aggregation in numerical simulations: A review. Surv. Geophys., 38, 1173-1197, https://doi.org/10.1007/ s10712-017-9408-4.

Wood, R., and P. R. Field, 2011: The distribution of cloud horizontal sizes. J. Climate, 24, 4800-4816, https://doi.org/10.1175/ 2011JCLI4056.1.

Zängl, G., D. Reinert, P. Rípodas, and M. Baldauf, 2015: The ICON (Icosahedral Non-hydrostatic) modelling framework of DWD and MPI-M: Description of the non-hydrostatic dynamical core. Quart. J. Roy. Meteor. Soc., 141, 563-579, https:// doi.org/10.1002/qj.2378.

Zhang, Y., and Coauthors, 2008: On the diurnal cycle of deep convection, high-level cloud, and upper troposphere water vapor in the Multiscale Modeling Framework. J. Geophys. Res., 113, D16105, https://doi.org/10.1029/2008JD009905. 